\title{
Thermodynamic, Raman Spectroscopic and UV-Visible Optical Characterization of the Deltic, Squaric and Croconic Cyclic Oxocarbon Acids
}

\author{
Francisco Colmenero* and Rafael Escribano \\ Instituto de Estructura de la Materia (IEM-CSIC). C/ Serrano, 113. 28006 - Madrid, Spain
}

\begin{abstract}
A precise and complete thermodynamic, Raman spectroscopic and ultraviolet-visible optical characterization of the deltic, squaric and croconic cyclic oxocarbon acids is obtained using theoretical solid-state methods employing very demanding calculation parameters. The computed fundamental thermodynamic properties include the isobaric specific heat, the entropy, the enthalpy and the Gibbs free energy as a function of temperature. The calculated specific heats at $298.15 \mathrm{~K}$ of the deltic, squaric and croconic acids are 89.7, 111.2 and $133.2 \mathrm{~J} \cdot \mathrm{mol}^{-1} \cdot \mathrm{K}^{-1}$, respectively, and the corresponding entropies are $98.3,117.3$ and $136.5 \mathrm{~J} \cdot$ $\mathrm{mol}^{-1} \cdot \mathrm{K}^{-1}$. The only value of these properties known from experimental measurements is the specific heat of the squaric acid which differs from the computed value at $315 \mathrm{~K}$ by about $4.9 \%$. The calculated values of the thermodynamic properties are then used to determine the thermodynamic properties of formation of these materials in terms of the elements. As an application of the calculated thermodynamic properties of formation, the Gibbs free energies of reaction and associated reaction constants are evaluated for the reactions of thermal decomposition and complete combustion of the squaric and croconic acids and the reaction of interconversion between them. The only available experimental values of these properties, namely the enthalpies of combustion of squaric and croconic acids at room temperature, are reproduced theoretically with high accuracy. The Raman spectra of these materials are also computed using Density Functional Perturbation Theory. The analysis of the theoretical Raman spectra of these materials points out to significant differences with respect to their usual empirical assignment. Therefore, the Raman spectra of these materials is fully reassigned. Finally, the ultraviolet-visible (UV-Vis) optical properties of the deltic, squaric and croconic acids are computed. The UV-Vis absorption spectrum of the croconic acid in the spectral region 225-425 nm and the UV absorption spectrum of the squaric acid in the region 200-350 $\mathrm{nm}$ which had previously been measured experimentally are well reproduced. The corresponding spectrum for the deltic acid and the reflectivity, optical conductivity, dielectric, refractive index and loss optical functions of the three materials, which had never been published as far as we know, are reported as a function of the wavelength of incident radiation in the range 200-750 $\mathrm{nm}$. The origin of the peaks in the absorption spectra which had not been analyzed so far is unveiled here by examining the inter-band electronic transitions in these materials.
\end{abstract}

\section{INTRODUCTION}

The cyclic oxocarbon acids ${ }^{1-6}\left(\mathrm{C}_{\mathrm{n}} \mathrm{O}_{\mathrm{n}} \mathrm{H}_{2}, n=3,4,5,6\right)$ have long been studied in the last decades and have been employed in a wide range of scientific, technological and biomedical applications. A review of the literature has been reported in a previous work. ${ }^{6}$ However, the analysis of the literature revealed the existence of several significant pieces of knowledge concerning these materials which are almost completely unknown. The first one, the mechanical behavior of these materials, was addressed in the previous work. ${ }^{6}$ The second one is their fundamental thermodynamic properties and the third one is their ultraviolet-visible (UV-Vis) optical spectra and properties. Finally, although the Raman spectra of these materials have been recorded experimentally in many previous works, ${ }^{7-23}$ the band assignments were founded on empirical arguments only. The results obtained in the present theoretical solid-state calculations of the deltic, squaric and croconic acids $(n=3,4$ and 5, respectively), pointed out to significant problems in their assignment. Therefore, the Raman spectra of these materials were reassigned. Of course, this feature is not a critique to the excellent spectroscopic works performed so $\operatorname{far}^{7-23}$ for these materials but to the empirical method of assignment which is too rough to provide the correct spectral interpretations in many occasions. ${ }^{24-}$ ${ }^{25}$ The extrapolation of spectroscopic data from gas phase molecule to solid state materials is a very crude approximation indeed. Likewise, the use of normal-coordinate treatments based on approximate force field methods ${ }^{8,10,11,14,15,21}$ may lead to significant errors in the calculated spectra of solid materials and their assignment.

The fundamental thermodynamic properties computed in this work include the isobaric specific heat, the entropy, the enthalpy and the Gibbs free energy as well as their temperature dependence. The results obtained for the thermodynamic properties where then used to determine the thermodynamic properties of formation of these materials in terms of the elements. Despite their importance, the majority of the thermodynamic properties of these materials and their temperature dependence are unknown. ${ }^{26-33}$ In a subsequent step, the calculated thermodynamic properties of formation were used to evaluate the Gibbs free energies of reaction and associated reaction constants for the reactions of thermal decomposition of the squaric and croconic acids:

(A) $\mathrm{H}_{2} \mathrm{C}_{4} \mathrm{O}_{4}$ (cr) $\rightarrow 2 \mathrm{CO}(\mathrm{g})+1 / 2 \mathrm{CO}_{2}$ (g) $+3 / 2 \mathrm{C}$ (cr) $+\mathrm{H}_{2} \mathrm{O}$ (l)

(B) $\mathrm{H}_{2} \mathrm{C}_{5} \mathrm{O}_{5}$ (cr) $\rightarrow 3 \mathrm{CO}(\mathrm{g})+1 / 2 \mathrm{CO}_{2}$ (g) $+3 / 2 \mathrm{C}(\mathrm{cr})+\mathrm{H}_{2} \mathrm{O}(\mathrm{l})$

their reactions of complete combustion:

(C) $\mathrm{H}_{2} \mathrm{C}_{4} \mathrm{O}_{4}$ (cr) $+5 / 2 \mathrm{O}_{2}$ (g) $\rightarrow 4 \mathrm{CO}_{2}$ (g) $+\mathrm{H}_{2} \mathrm{O}(\mathrm{l})$

(D) $\mathrm{H}_{2} \mathrm{C}_{5} \mathrm{O}_{5}$ (cr) $+3 \mathrm{O}_{2}$ (g) $\rightarrow 5 \mathrm{CO}_{2}(\mathrm{~g})+\mathrm{H}_{2} \mathrm{O}$ (l)

and the reaction of conversion between them in the presence of carbon monoxide:

(E) $\mathrm{H}_{2} \mathrm{C}_{4} \mathrm{O}_{4}$ (cr) $+\mathrm{CO}$ (g) $\rightarrow \mathrm{H}_{2} \mathrm{C}_{5} \mathrm{O}_{5}$ (cr)

as a function of temperature. The thermodynamic parameters of organic compounds are extraordinarily important not only in 
several scientific fields such as organic reactivity but also for many specific applications as the development of novel energetic materials. ${ }^{34-35}$ Croconic acid, in particular, has been found to be useful for the next generation of gun propellants which substantially increase the muzzle velocity. ${ }^{34-35}$ The oxocarbon acids are very relevant materials in organic reactivity studies. ${ }^{36}$

The good results obtained for the structural properties of these materials in the previous work ${ }^{6}$ encouraged the determination of their mechanical properties. These acids in the solid state were shown to display negative Poisson ratios (NPR) ${ }^{37-39} \mathrm{Be}-$ sides, the croconic acid also exhibits the phenomenon of negative linear compressibility (NLC) ${ }^{40-42}$ for applied pressures larger than $0.4 \mathrm{GPa}$ directed along the direction of minimum Poisson ratio. The materials displaying the NPR and NLC phenomena have an enormous range of applications owing to their exclusive mechanical properties. ${ }^{6}$ These facts emphasize the need of determining the corresponding thermodynamic data of the cyclic oxocarbon acids required to optimize its production and to investigate their chemical behavior in the presence of different chemical reagents.

While the UV-Vis absorption spectrum of the croconic acid in the spectral region $225-425 \mathrm{~nm}$ and the UV absorption spectrum of the squaric acid in the region 200-350 nm have been measured experimentally, ${ }^{43-44}$ the corresponding spectrum for the deltic acid and the reflectivity, optical conductivity, dielectric, refractive index and loss optical functions ${ }^{45-47}$ of the three materials are unknown. The great relevance of the small organic acids in the description of global atmospheric chemistry, the influence of their presence in the optical characteristics of the atmospheres $^{43}$ and the use of compounds closely related to the cyclic oxocarbon acids, as squaraines and croconines, as dyes ${ }^{48-}$ ${ }^{53}$ which may be employed as optical sensors underlines the importance of the precise knowledge of their optical properties. For example, it has been proposed that the croconic acid is a contaminant in the sulfuric acid cloud droplets in the Venus clouds and may represent the absorber responsible for the ultraviolet cloud features and the pale-yellow color of the Venus clouds. ${ }^{43}$ The origin of the peaks in the absorption spectra of the deltic, squaric and croconic acids which has not been analyzed so far is unveiled here by examining the inter-band electronic transitions in these materials.

The main purpose of this study is to complement the relatively poor current experimental characterization of these important materials. This paper is organized as follows. In Section II, the theoretical solid-state methods used in this work are described. Then, in Section III, the main results of this work are given and discussed. This section contains three main Subsections in which the thermodynamic, optical and spectroscopic results are studied separately. Finally, in Section IV, the conclusions of this work are presented.

\section{THEORY}

\section{II.1 Crystal structures and Raman Spectra}

Periodic Density Functional Theory (DFT) methods based on plane wave basis sets and pseudopotentials ${ }^{54}$ were employed in order to model the crystal structures of the cyclic oxocarbon acids. ${ }^{6}$ Thus, the generalized gradient approximation (GGA) together with Perdew-Burke-Ernzerhof functional ${ }^{55}$ supplemented with Grimme empirical dispersion correction, ${ }^{56}$ was used. The computations were carried out with very exigent computational parameters in order to obtain very precise crystal structures and values of the thermodynamic, optical and Raman spectroscopic properties of these materials. The technical details of the corresponding computational treatments may be found in the previous paper. ${ }^{6}$ The optimized crystal structures of deltic, squaric, and croconic acids were very accurate and the computed X-ray powder diffraction patterns were in excellent agreement with their experimental counterparts. ${ }^{6}$ The computed crystal structures are displayed in Figure 1. For the calculations of the Raman spectra, the linear response density functional perturbation theory (DFPT), ${ }^{57-59}$ implemented in the CASTEP code,${ }^{60}$ a module of Materials Studio package, ${ }^{61}$ was used in the same way as in previous works. ${ }^{2-25,62-67}$ The theoretical solidstate methodology used in this paper has been employed not only for organic and metal-organic materials ${ }^{6.24-25,68-71}$ but also for a large series of uranyl containing compounds as oxides, ${ }^{72}$ oxyhydroxides, ${ }^{73-77}$ peroxides, ${ }^{63}$ carbonates $^{62,78-79}$ and silicates. ${ }^{64-65}$ In all these cases the results were very satisfactory.

\section{II.2. Fundamental thermodynamic properties}

In order to determine the thermodynamic properties of these materials, phonon calculations were carried out at their optimized structures. The phonon spectrum at different points of the Brillouin zone were obtained employing the Density Functional Perturbation Theory (DFPT) technique as second order derivatives of the total energy. ${ }^{80}$ The phonon dispersion curves and density of states were computed from the phonon spectra and, using these results, several important thermodynamic properties in the quasi-harmonic approximation, namely the Gibbs free energies, enthalpies, entropies, and specific heats, were evaluated. ${ }^{80,24-25.72,78}$ The thermodynamic properties of formation and reaction will be evaluated in terms of the calculated fundamental thermodynamic properties using the methods described in the next subsections. ${ }^{72-73,81}$

\section{II.3. Thermodynamic properties of formation}

The enthalpies and Gibbs free-energies of formation in terms of the elements were determined, from the computed enthalpy and entropy functions, $\left(H_{T}-H_{298}\right)^{\text {calc }}$ and $S_{T}^{\text {calc }}$, by means of the relationships: ${ }^{82,72}$
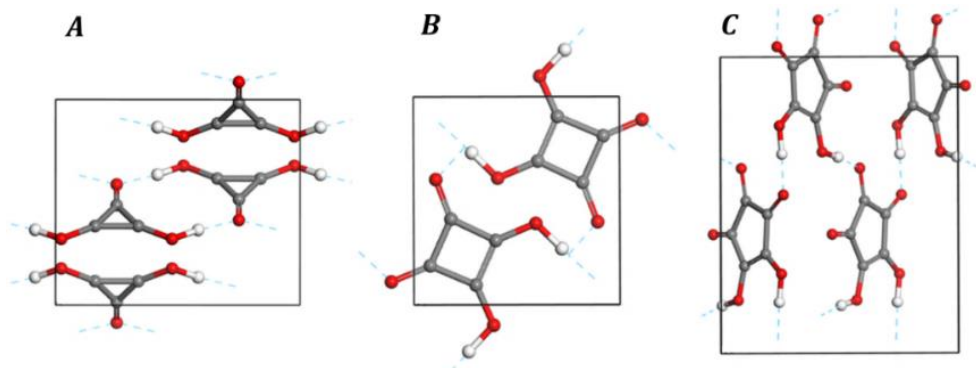

Figure 1. Calculated crystal structures of (A) deltic, (B) squaric and (C) croconic acids: Views of the corresponding unit cells from [010] crystallographic direction. Color code: Grey-C; Red-O; White-H. 


$$
\begin{aligned}
& \Delta_{f} H(T)=\Delta_{f} H^{0}+\left(H_{T}-H_{298}\right)^{\text {calc }} \\
&+\sum_{i}^{\text {elements }} n_{i}\left(H_{T}-H_{298}\right)_{i}^{\text {exp }} \\
& \Delta_{f} G(T)=\Delta_{f} H(T)-T\left\{S_{T}^{\text {calc }}-\sum_{i}^{\text {elements }} n_{i}\left(S_{T}\right)_{i}^{\text {exp }}\right\}
\end{aligned}
$$

In these equations, $\Delta_{f} H^{0}$ is the enthalpy of formation at the standard state of the material being considered, and $\left(H_{T}-\right.$ $\left.H_{298}\right)_{i}^{\text {exp }}$ and $\left(S_{T}\right)_{i}^{\text {exp }}$ are the enthalpy and entropy functions of the elements forming part of this material with stoichiometric coefficients $n_{i}$, respectively. For a pure substance, the concept of standard state applies to the substance in a well-defined state of aggregation at a well-defined but arbitrarily chosen standard pressure (usually chosen as 1 bar). Therefore, the definition of standard state makes no reference to a fixed temperature. However, it is usually convenient to complete the definition of the standard state in a particular context by choosing a value for the reference temperature. ${ }^{83}$ The most usually recommended value is $298.15 \mathrm{~K}$. The precise values used for $\Delta_{f} H^{0}$ will be given below. The thermodynamic functions for carbon, oxygen and hydrogen were taken from JANAF (Joint Army-Navy-Air Force) thermochemical tables. ${ }^{82}$ The reaction constants of the formation reactions were calculated from the corresponding Gibbs free energies of formation employing the relationship: ${ }^{82}$

$$
\Delta G(T)=-R T \operatorname{Ln} K
$$

\section{II.4. Thermodynamic properties of reaction}

The enthalpies and Gibbs free energies of reaction at different temperatures were obtained, using our computed values of the Gibbs free energies and entropies of formation functions, $\Delta_{f} G(T)^{\text {calc }}$ and $\Delta_{f} S(T)^{\text {calc }}$, by means of the expressions: ${ }^{82,73}$

$$
\begin{gathered}
\Delta_{r} G(T)=\sum_{i}^{\text {products }} n_{i} \Delta_{f} G^{i}(T)-\sum_{j}^{\text {reactants }} n_{j} \Delta_{f} G^{j}(T) \\
\Delta_{r} H(T)=\Delta_{r} G(T)+T \cdot \Delta_{r} S(T)
\end{gathered}
$$

where,

$$
\Delta_{r} S(T)=\sum_{i}^{\text {products }} n_{i} \Delta_{f} S^{i}(T)-\sum_{j}^{\text {reactants }} n_{j} \Delta_{f} S^{j}(T)
$$

In these relations, $\Delta_{f} G^{i}(T)$ and $\Delta_{f} S^{i}(T)$, are the Gibbs free energy and entropy of formation at temperature $\mathrm{T}$ of compound $i$ participating in the reaction with stoichiometric coefficient $n_{i}$. The thermodynamic functions for $\mathrm{CO}(\mathrm{g}), \mathrm{CO}_{2}(\mathrm{~g}), \mathrm{H}_{2} \mathrm{O}(\mathrm{l})$, $\mathrm{O}_{2}$ (g) and $\mathrm{C}(\mathrm{cr})$ were taken from JANAF thermochemical tables. ${ }^{82}$ The reaction constants were calculated from the Gibbs free energies of reaction by using equation (3).

\section{II.5. Optical properties}

The propagation of an electromagnetic wave through a certain material can be described by a complex refractive index, ${ }^{47-49}$ $N=n+i \cdot k$. For propagation in vacuum $N$ is real and equal to unity. The imaginary part $k$ is related to the absorption coefficient $\alpha$ by $\alpha=2 k \omega / c$, where $\omega$ is the frequency of the electromagnetic wave and $c$ is the speed of light. The absorption coefficient gives the fraction of wave energy lost when it passes through the material. For normal incidence of the radiation wave on the material surface, the radiation intensity at the distance $x$ from the surface is $I(x)=I(0) \cdot \exp (-2 \pi \alpha x)$, where $I(0)$ is the initial intensity of the incident light. For normal incidence of the radiation onto a material plane surface, the reflection coefficient is related to the refractive index:

$$
R=\left|\frac{1-N}{1+N}\right|^{2}=\frac{(n-1)^{2}+k^{2}}{(n+1)^{2}+k^{2}}
$$

Theoretically, to obtain the optical properties of a material, the complex dielectric constant is obtained in the first place and then the remaining optical properties are determined from it. The complex dielectric constant $\varepsilon$ is related to the refractive in$\operatorname{dex}$ by $\varepsilon=\varepsilon_{1}+i \cdot \varepsilon_{2}=N^{2}$. Hence,

$$
\varepsilon_{1}=n^{2}-k^{2} ; \varepsilon_{2}=2 n k
$$

The optical properties are also usually expressed in terms of the optical conductivity $\sigma$

$$
\sigma_{1}=\sigma_{1}+i \cdot \sigma_{2}=i \frac{\omega}{4 \pi}(\varepsilon-1)
$$

The loss function $\xi$ describing the energy lost by an electron crossing the considered material is expressed in terms of the dielectric function as

$$
\xi=\operatorname{Im}\left(-\frac{1}{\varepsilon}\right)
$$

The interaction of a photon with a material may be described as a time dependent perturbation of the ground state electronic state. The approach implemented in CASTEP with this purpose is the time dependent density functional theory (TD-DFT) ${ }^{84}$ The main approximation performed in this approach is the neglect of local field effects, arising from the fact that the electric field experienced at a particular site in the material is screened by the polarizability of the system itself. While these effects might also be accounted for, the corresponding computations could become prohibitively expensive.

\section{RESULTS AND DISCUSION}

\section{III.1. Thermodynamic characterization}

\section{III.1.1. Fundamental thermodynamic properties}

The calculated isobaric specific heats $\left(C_{p}\right)$, entropies $(S)$, enthalpies $(H)$ and Gibbs free energies $(G)$ of the deltic acid are displayed in Figures 2.A, 2.B, 2.C and 2.C, respectively. Similarly, the computed thermodynamic properties of the squaric and croconic acids are shown in Figures 3.A-3.D and 4.A-4.D, respectively. The values of enthalpy and Gibbs free energy were divided by the temperature to express these properties using the same units as for $C_{p}$ and $S\left(\mathrm{~J} \cdot \mathrm{K}^{-1} \cdot \mathrm{mol}^{-1}\right)$. The precise values of the computed thermodynamic properties over the temperature range $0-1000 \mathrm{~K}$ for the deltic and croconic acids and 0-350 $\mathrm{K}$ for the squaric acid (this material undergoes an antiferroelectric phase transition near $373 \mathrm{~K})^{85-88}$ are provided in Tables S.1 to S.12 of the Supporting Information.

Since the most part of the thermodynamic properties of these materials have never been measured experimentally, their values were predicted. The calculated specific heats and entropies at $298.15 \mathrm{~K}$ are reported in Table 1 . The calculated specific heats at $298.15 \mathrm{~K}$ of the deltic, squaric and croconic acids are $89.7,111.2$ and $133.2 \mathrm{~J} \cdot \mathrm{K}^{-1} \cdot \mathrm{mol}^{-1}$, respectively, and the corresponding entropies are $98.3,117.3$ and $136.5 \mathrm{~J} \cdot \mathrm{K}^{-1}$. $\mathrm{mol}^{-1}$. The only thermodynamic property which is known from experiment is the specific heat of squaric acid. ${ }^{89-90,30}$ The experimental and computed values at $315 \mathrm{~K}\left(C_{p}^{\text {exp }}=121.6 \mathrm{~J} \cdot \mathrm{K}^{-1}\right.$. $\mathrm{mol}^{-1}$ and $C_{p}^{\text {calc }}=115.6 \mathrm{~J} \cdot \mathrm{K}^{-1} \cdot \mathrm{mol}^{-1}$, respectively) agree satisfactorily, the values differing by about $4.9 \%$. The calculated specific heats of deltic and croconic acids at the highest temperature considered in the present work $(1000 \mathrm{~K}), 166.6$ and $249.6 \mathrm{~J} \cdot \mathrm{K}^{-1} \cdot \mathrm{mol}^{-1}$, respectively, are 16.5 and $16.6 \%$ below the corresponding Dulong-Petit asymptotic limits (199.5 and $299.3 \mathrm{~J} \cdot \mathrm{K}^{-1} \cdot \mathrm{mol}^{-1}$ ). 
Table 1. Calculated specific heats and entropies of the deltic, squaric and croconic acids at 298.15 K. All values are given in units of $\mathrm{J} \cdot \mathrm{K}^{-1} \cdot \mathrm{mol}^{-1}$.

\begin{tabular}{ccc}
\hline Material & $\boldsymbol{C}_{\boldsymbol{p}}^{\text {calc }}$ & $\boldsymbol{S}^{\text {calc }}$ \\
\hline Deltic acid & 89.66 & 98.30 \\
Squaric acid & 111.18 & 117.30 \\
Croconic acid & 133.21 & 136.53 \\
\hline
\end{tabular}
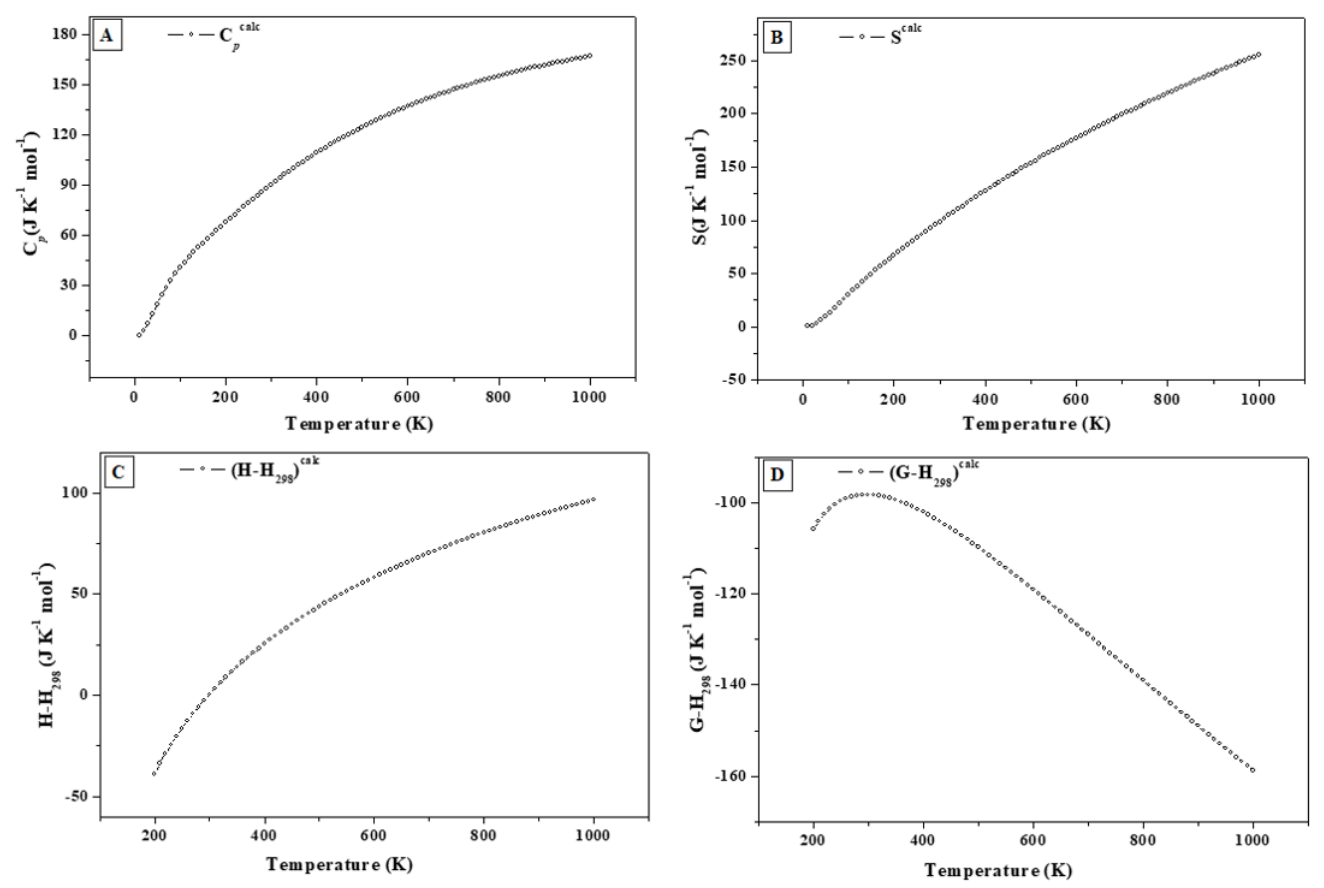

Figure 2. Calculated thermodynamic properties of the deltic acid: A) isobaric specific heat; B) entropy; C) enthalpy; and D) Gibbs free energy, as functions of temperature.
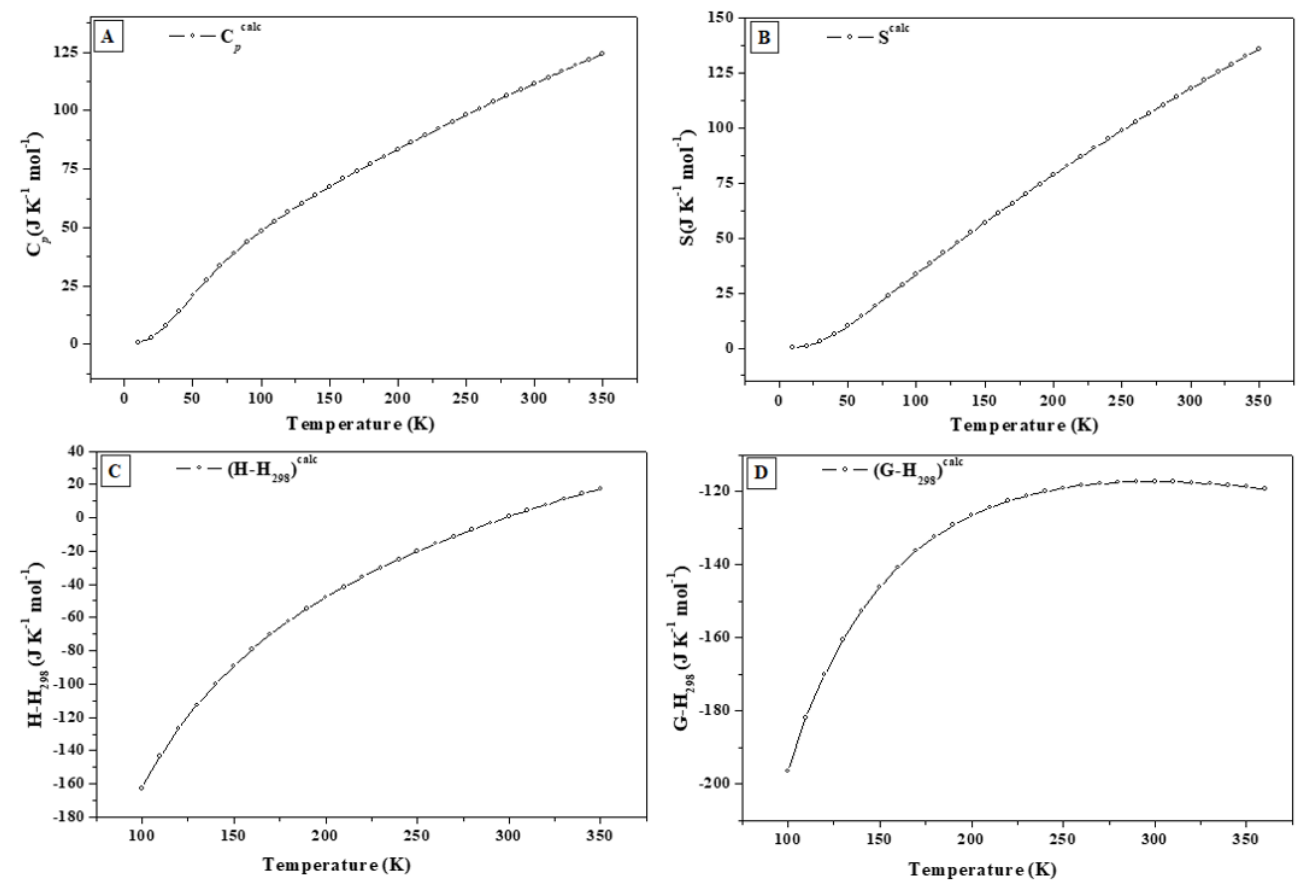

Figure 3. Calculated thermodynamic properties of the squaric acid: A) isobaric specific heat; B) entropy; C) enthalpy; and D) Gibbs free energy, as functions of temperature. 

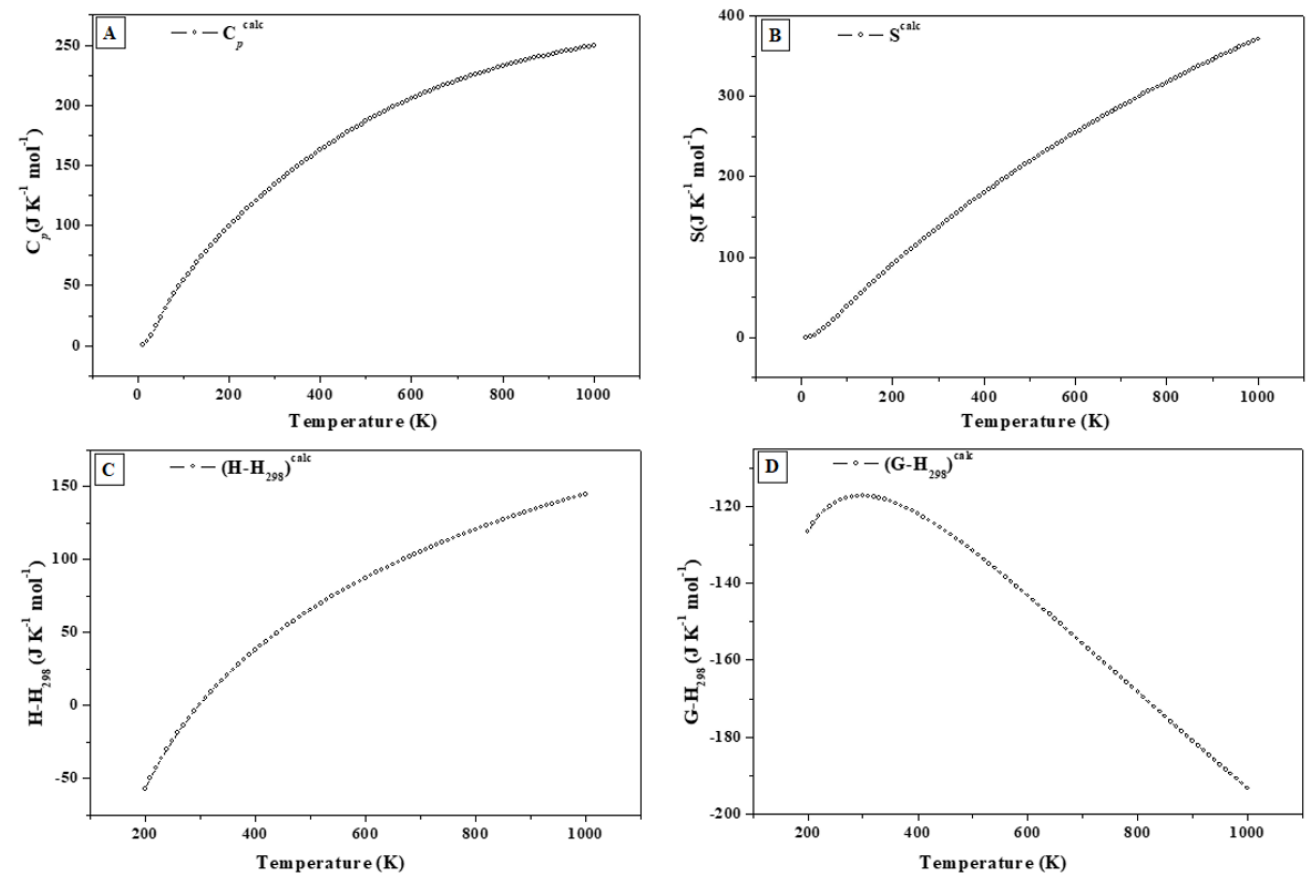

Figure 4. Calculated thermodynamic properties of the croconic acid: A) isobaric specific heat; B) entropy; C) enthalpy; and D) Gibbs free energy, as functions of temperature.

The expected accuracy for the computed isobaric specific heats and entropies given in Table 1 may be assessed from the analysis of the previous results obtained using the same methodology for materials in which the corresponding experimental values are available. This analysis has already been performed for uranyl containing materials. ${ }^{81}$ The expected accuracy is better than $3-5 \%$ for the computed specific heats and entropies at $298 \mathrm{~K}^{81}$ The fundamental thermodynamic properties were also determined using the same methodology for non-uranyl containing materials as natroxalate and oxammite minerals. ${ }^{24-25}$ The results were found to be very good and to be within the above mentioned expected accuracy. The difference found in this work for the computed specific heat of squaric acid with respect to the experimental value at $315 \mathrm{~K}(4.9 \%)$ is also within this estimated accuracy. The temperature dependence of these properties is also expected to be well described. For example, the computed specific heat and entropy of uranium trioxide ${ }^{72,81}$ were in excellent agreement with experimental data in the full range of temperatures considered $0-1000 \mathrm{~K}$. The differences were $3.9 \%$ and $1.8 \%$ at $100 \mathrm{~K}$ and $6.1 \%$ and $3.6 \%$ at $1000 \mathrm{~K}$, respectively.

\section{III.1.2. Thermodynamic properties of formation}

The enthalpies of formation of the squaric and croconic acids at the standard state are known from experimental data. ${ }^{91,34-35}$ The corresponding values are $\Delta_{f} H^{0}\left(\mathrm{H}_{2} \mathrm{C}_{4} \mathrm{O}_{4}(\mathrm{cr})\right)=-598.2 \pm 0.4$ $\mathrm{kJ} \cdot \mathrm{mol}^{-1}$ and $\Delta_{f} H^{0}\left(\mathrm{H}_{2} \mathrm{C}_{5} \mathrm{O}_{5}(\mathrm{cr})\right)=-817.41 \pm 1 \mathrm{~kJ} \cdot$ $\mathrm{mol}^{-1} \cdot{ }^{91,34-35}$ It is important to note that the value reported by Sellers ${ }^{91}$ for squaric acid, was unnoticed in the review works by Domalsky et al. ${ }^{28-30}$ Using these values, the computed enthalpy and entropy functions of the squaric and croconic acids and the experimental thermodynamic properties of the corresponding elements from Chase et al., ${ }^{82}$ the enthalpies and Gibbs free energies of formation in terms of the elements were derived. The calculated values are given in Table 2 . The Gibbs free energies of formation are shown in Figure 5. For the deltic acid, since the experimental value of the enthalpy of formation appears not to have been measured, the values given in Table 2 are those of
$\left(\Delta_{f} H(T)-\Delta_{f} H^{0}\right)$ and $\left(\Delta_{f} G(T)-\Delta_{f} H^{0}\right)$. If the experimental value of $\Delta_{f} H^{0}\left(\mathrm{H}_{2} \mathrm{C}_{3} \mathrm{O}_{3}(\mathrm{cr})\right)$ is determined from accurate experimental measurements in the future, the full temperature dependent thermodynamic properties of formation of the deltic acid could be evaluated directly by adding this parameter to the values reported in Table 2 .

The calculated temperature dependent thermodynamic properties of formation given in Table 2 are also expected to be accurate. In this case, the expected accuracy is about $3 \%$. This estimate was obtained ${ }^{81}$ from the analysis of the results obtained using the same methodology for the thermodynamic functions of formation of rutherfordine, uranium trioxide and metaschoepite, the latter being a very complex uranyl containing material. ${ }^{76}$ For these materials, the differences of the calculated and experimental values of the Gibbs free energies of formation were lower than $1 \%$ at ambient temperature and the differences remained very small at high temperatures. These differences were $1.6 \%, 1.0 \%$, and $2.0 \%$ at 700,900 , and $800 \mathrm{~K}$, respectively. ${ }^{81}$

III.1.3. Thermodynamic properties of the reactions of thermal decomposition of squaric and croconic acids [(A)-(B)].

Among the different possible thermal decomposition reactions, only the reactions (A) and (B) have been shown to have an stoichiometry compatible with the experimentally observed percent of residual carbon resulting from the thermal treatment of the these acids. ${ }^{92}$ These reactions state that under heating, one formula unit of these acids decompose into 2 (3) formula units of carbon monoxide, 1/2 of carbon dioxide, $3 / 2$ of carbon and one of water. From the thermodynamic properties of formation in terms of the elements reported in the previous subsection III.2 and the experimental thermodynamic properties of $\mathrm{CO}(\mathrm{g})$, $\mathrm{CO}_{2}(\mathrm{~g}) \mathrm{H}_{2} \mathrm{O}(\mathrm{l})$, and $\mathrm{C}(\mathrm{cr})$ taken from JANAF thermochemical tables, ${ }^{82}$ the Gibbs free energies of reaction and associated reaction constants of the reactions of thermal decomposition of 
the squaric and croconic acids may be determined. The calculated values are given in Table 3 and shown in Figure 6.

III.1.4. Thermodynamic properties of the reactions of complete combustion of squaric and croconic acids [(C)-(D)]. Enthalpies of combustion

Following the same scheme as in Subsection III.1.3, the corresponding reaction parameters for reactions (C) and (D) were calculated. Thus, from the computed thermodynamic properties of formation in terms of the elements and the experimental thermodynamic properties for $\mathrm{CO}_{2}(\mathrm{~g}), \mathrm{H}_{2} \mathrm{O}(\mathrm{l})$, and $\mathrm{O}_{2}(\mathrm{cr})$ taken from JANAF thermochemical tables,${ }^{82}$ the Gibbs free energies of reaction and associated reaction constants of the reactions of complete combustion of the squaric and croconic acids, (C) and (D), were obtained. The calculated thermodynamic properties of reaction are provided in Table 4 and plotted in Figure 7.

The computed value of the combustion enthalpies at room temperature are $\Delta_{r}^{c} H^{0}\left(\mathrm{H}_{2} \mathrm{C}_{4} \mathrm{O}_{4}(\mathrm{cr})\right)=-1261.70 \mathrm{~kJ} \cdot \mathrm{mol}^{-1}$ and $\Delta_{r}^{c} H^{0}\left(\mathrm{H}_{2} \mathrm{C}_{5} \mathrm{O}_{5}(\mathrm{cr})\right)=-1436.01 \mathrm{~kJ} \cdot \mathrm{mol}^{-1}$ for the squaric and croconic acids, respectively. These values agree very well with the experimental values reported by Sellers, ${ }^{91}-1261.67 \pm 0.33$
$\mathrm{kJ} \cdot \mathrm{mol}^{-1}$ and Ciezak-Jenkins et al. ${ }^{34-35},-1436 \mathrm{~kJ} \cdot \mathrm{mol}^{-1}$, for the squaric and croconic acids, respectively. The excellent agreement between these values gives strong support to the computed values of the thermodynamic properties of the cyclic oxocarbon acids reported in this article because the combustion enthalpies of organic compounds are generally determined experimentally with high accuracy.

III.1.5. Thermodynamic properties of the reaction of conversion between squaric and croconic acids $[(\mathrm{E})]$

Again, from the computed thermodynamic properties of formation in terms of the elements of the squaric and croconic acids and the experimental thermodynamic properties for $\mathrm{CO}(\mathrm{g})$, taken from JANAF thermochemical tables, ${ }^{82}$ the Gibbs free energies of reaction and associated reaction constants of the reaction (E) were calculated. These properties are listed in Table 5 and displayed in Figure 8. Since the enthalpies and free energies of this reaction are negative for the full range of temperatures considered, this reaction should be exothermic and spontaneous. This suggests a way to obtain the croconic acid from the squaric acid submitted to high carbon monoxide gas pressures.

Table 2. Calculated enthalpies $\left(\Delta_{f} H\right)$ and free energies $\left(\Delta_{f} G\right)$ of formation and reaction constants (Log K) for the deltic, squaric and croconic acids. The values of $\Delta_{f} H$ and $\Delta_{f} G$ are in units of $\mathrm{kJ} / \mathrm{mol}$.

\begin{tabular}{ccccccccc}
\hline \multirow{2}{*}{$\mathbf{T}(\mathbf{K})$} & \multicolumn{2}{c}{ Deltic acid } & \multicolumn{3}{c}{ Squaric acid } & \multicolumn{3}{c}{ Croconic acid } \\
\cline { 2 - 9 } & $\Delta_{\boldsymbol{f}} \boldsymbol{H}-\Delta_{\boldsymbol{f}} \boldsymbol{H}^{\mathbf{0}}$ & $\Delta_{\boldsymbol{f}} \boldsymbol{G}-\Delta_{\boldsymbol{f}} \boldsymbol{H}^{\mathbf{0}}$ & $\Delta_{\mathbf{f}} \mathbf{H}$ & $\Delta_{\mathbf{f}} \mathbf{G}$ & Log K & $\Delta_{\mathbf{f}} \mathbf{H}$ & $\Delta_{\mathbf{f}} \mathbf{G}$ & Log K \\
\hline 298.15 & 0.00 & 106.54 & -598.20 & -465.04 & 81.47 & -817.41 & -657.68 & 115.22 \\
50 & -274.98 & -262.20 & -933.82 & -917.85 & 958.85 & -1212.69 & -1193.58 & 1246.89 \\
100 & -115.41 & -82.05 & -739.91 & -698.16 & 364.67 & -985.18 & -935.11 & 488.44 \\
200 & -29.68 & 40.68 & -634.92 & -546.92 & 142.84 & -861.44 & -755.81 & 197.39 \\
300 & 0.38 & 107.59 & -597.73 & -463.72 & 80.74 & -816.85 & -656.11 & 114.24 \\
350 & 8.78 & 134.22 & -587.27 & -430.51 & 64.25 & -804.28 & -616.30 & 91.97 \\
400 & 14.75 & 158.25 & - & - & - & -795.34 & -580.32 & 75.78 \\
450 & 18.87 & 180.28 & - & - & - & -789.15 & -547.31 & 63.53 \\
500 & 21.55 & 200.72 & - & - & - & -785.13 & -516.66 & 53.97 \\
550 & 23.07 & 219.85 & - & - & - & -782.86 & -487.96 & 46.34 \\
600 & 23.65 & 237.92 & - & - & - & -782.03 & -460.85 & 40.12 \\
650 & 23.43 & 255.05 & - & - & - & -782.41 & -435.13 & 34.97 \\
700 & 22.51 & 271.37 & - & - & - & -783.85 & -410.65 & 30.64 \\
750 & 20.97 & 286.93 & - & - & - & -786.28 & -387.29 & 26.97 \\
800 & 18.84 & 301.79 & - & - & - & -789.62 & -364.99 & 23.83 \\
\hline
\end{tabular}
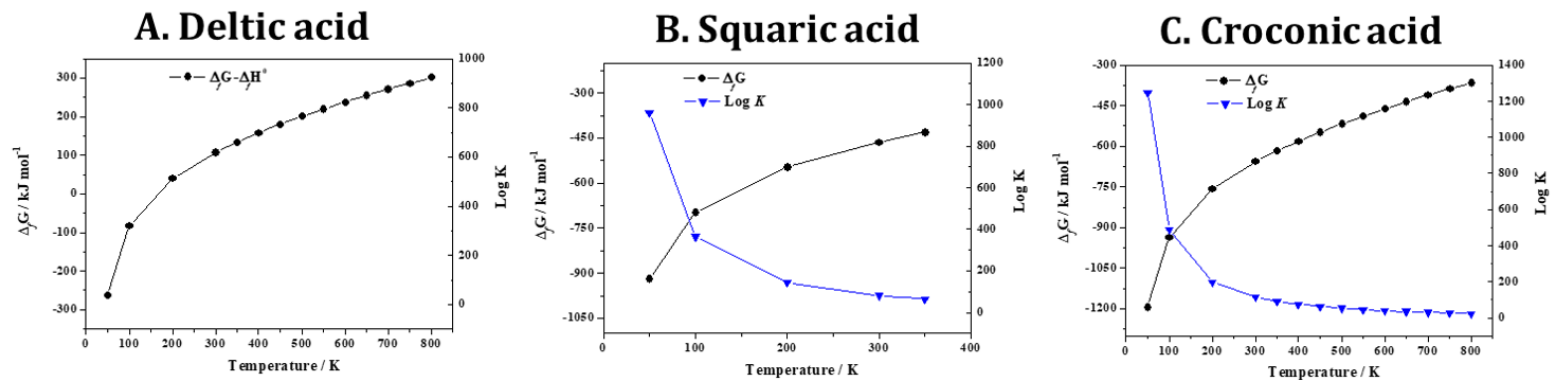

Figure 5. Calculated free energies of formation and associated reaction constants for the deltic, squaric and croconic acids as a function of temperature. 
Table 3. Calculated enthalpies $\left(\Delta_{r} H\right)$ and free energies $\left(\Delta_{r} G\right)$ of reaction and associated reaction constants (Log K) for the reactions of thermal decomposition of the squaric and croconic acids [(A) and (B)]. The values of $\Delta_{r} H$ and $\Delta_{r} G$ are in units of kJ/mol.

\begin{tabular}{|c|c|c|c|c|c|c|c|}
\hline \multirow{2}{*}{$\mathbf{T}(\mathbf{K})$} & \multicolumn{3}{|c|}{ Squaric acid. Reaction (A) } & \multirow{2}{*}{$\mathbf{T}(\mathbf{K})$} & \multicolumn{3}{|c|}{ Croconic acid. Reaction (B) } \\
\hline & $\Delta_{\mathrm{r}} \mathbf{H}$ & $\Delta_{\mathbf{r}} \mathbf{G}$ & $\log K$ & & $\Delta_{\mathbf{r}} \mathbf{H}$ & $\Delta_{\mathbf{r}} \mathbf{G}$ & $\log K$ \\
\hline 298.15 & -243.64 & -105.45 & 42.68 & 298.15 & 3.22 & -188.17 & 32.97 \\
\hline 310 & -252.03 & -107.71 & 42.46 & 320 & -1.85 & -208.57 & 34.05 \\
\hline 330 & -259.10 & -109.62 & 42.29 & 340 & -5.79 & -226.52 & 34.80 \\
\hline 330 & -265.69 & -111.05 & 42.05 & 360 & -9.24 & -243.97 & 35.40 \\
\hline 340 & -272.64 & -112.84 & 41.89 & 380 & -11.98 & -260.68 & 35.83 \\
\hline 350 & -279.28 & -114.32 & 41.68 & 400 & -14.36 & -277.03 & 36.17 \\
\hline 360 & -285.79 & -115.68 & 41.47 & 420 & -16.33 & -292.94 & 36.43 \\
\hline- & - & - & - & 440 & -17.93 & -308.46 & 36.62 \\
\hline - & - & - & - & 460 & -19.18 & -323.63 & 36.75 \\
\hline - & - & - & - & 480 & -20.11 & -338.47 & 36.83 \\
\hline- & - & - & - & 500 & -20.75 & -353.02 & 36.88 \\
\hline
\end{tabular}
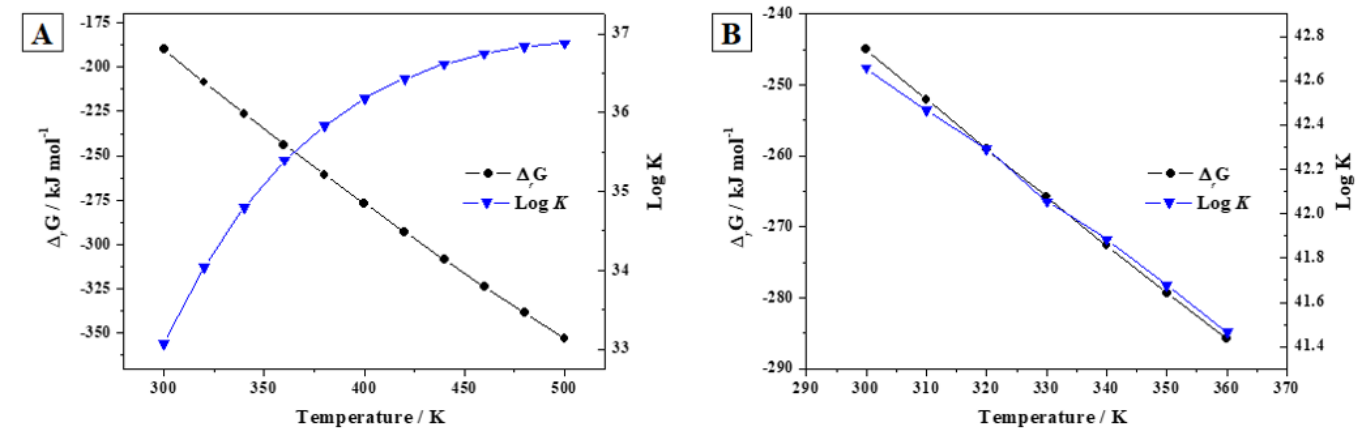

Figure 6. Calculated free energies and associated reaction constants for the reactions of thermal decomposition of squaric and croconic acids $[(\mathrm{A})$ and $(\mathrm{B})]$ as a function of temperature.

Table 4. Calculated enthalpies $\left(\Delta_{r} H\right)$ and free energies $\left(\Delta_{r} G\right)$ of reaction and associated reaction constants (Log K) for the reactions of complete combustion of the squaric and croconic acids [(C) and (D)]. The values of $\Delta_{r} H$ and $\Delta_{r} G$ are in units of kJ/mol.

\begin{tabular}{ccccccc}
\hline \multirow{2}{*}{ T(K) } & \multicolumn{3}{c}{ Squaric acid. Reaction (C) } & \multicolumn{3}{c}{ Croconic acid. Reaction (D) } \\
\cline { 2 - 7 } & $\Delta_{\mathbf{r}} \mathbf{H}$ & $\Delta_{\mathbf{r}} \mathbf{G}$ & $\mathbf{L o g} \mathbf{K}$ & $\Delta_{\mathbf{r}} \mathbf{H}$ & $\Delta_{\mathbf{r}} \mathbf{G}$ & Log K \\
\hline 298.15 & -1261.70 & -1349.65 & 236.45 & -1436.01 & -1551.40 & 271.79 \\
310 & -1264.03 & -1356.04 & 228.49 & -1441.53 & -1566.22 & 255.65 \\
320 & -1266.18 & -1361.42 & 222.22 & -1445.82 & -1579.03 & 242.58 \\
330 & -1267.44 & -1366.32 & 216.27 & -1449.58 & -1591.33 & 230.89 \\
340 & -1269.64 & -1371.57 & 210.71 & -1452.60 & -1602.89 & 220.33 \\
350 & -1271.23 & -1376.51 & 211.47 & -1455.20 & -1614.06 & 210.77 \\
360 & -1272.69 & -1381.32 & 200.42 & -1457.36 & -1624.78 & 202.07 \\
- & - & - & - & -1459.11 & -1635.11 & 194.11 \\
- & - & - & - & -1460.49 & -1645.07 & 186.80 \\
- & - & - & - & -1461.52 & -1654.70 & 180.06 \\
- & - & - & - & -1462.24 & -1664.02 & 173.84 \\
\hline
\end{tabular}



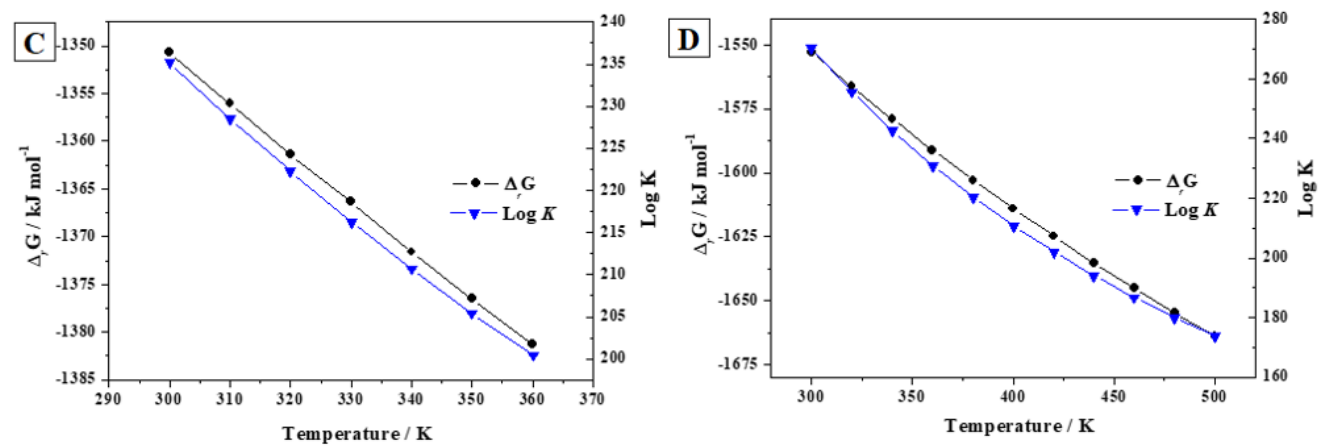

Figure 7. Calculated free energies and associated reaction constants for the reactions of complete combustion of the squaric and croconic acids $[(\mathrm{C})$ and $(\mathrm{D})]$ as a function of temperature.

Table 5. Calculated enthalpies $\left(\Delta_{r} H\right)$ and free energies $\left(\Delta_{r} G\right)$ of reaction and associated reaction constants (Log K) for the reaction of conversion between the squaric and the croconic acid in the presence of carbon monoxide [(E)]. The values of $\Delta_{r} H$ and $\Delta_{r} G$ are in units of $\mathrm{kJ} / \mathrm{mol}$.

\begin{tabular}{cccc}
\hline $\mathbf{T}(\mathbf{K})$ & $\Delta_{\mathbf{r}} \mathbf{H}$ & $\Delta_{\mathbf{r}} \mathbf{G}$ & $\log \mathbf{K}$ \\
\hline 298.15 & -108.67 & -55.47 & 9.72 \\
310 & -108.18 & -52.79 & 8.89 \\
320 & -107.77 & -50.52 & 8.25 \\
330 & -107.45 & -48.36 & 7.65 \\
340 & -107.06 & -46.12 & 7.09 \\
350 & -106.73 & -43.96 & 6.56 \\
360 & -106.44 & -41.83 & 6.07 \\
\hline
\end{tabular}

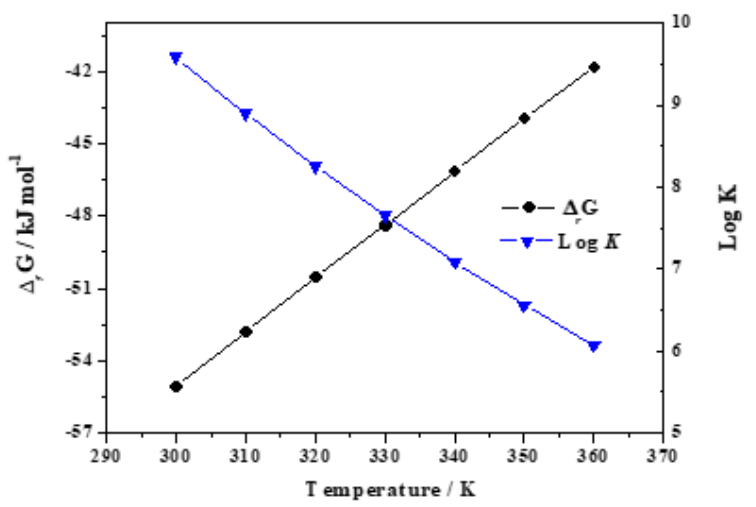

Figure 8. Calculated free energies and associated reaction constants for the reaction of conversion between the squaric and the croconic acid $[(\mathrm{E})]$ in the presence of carbon monoxide as a function of temperature. 


\section{III.2. Raman spectroscopic characterization}

\section{III.2.1. Deltic acid}

The experimental Raman spectrum of the deltic acid was recorded by Lautié $e t a l .^{7}$ from a synthetic sample obtained using the synthetic method of Serratosa. ${ }^{93}$ The Raman spectra was recorded employing a Raman spectrometer MOLE (Jobin-Yvon technology) using the $514.5 \mathrm{~nm}$ output of an $\mathrm{Ar}^{+}$laser as excitation source. The spectral resolution was $\pm 1 \mathrm{~cm}^{-1}$. The theoretical Raman spectrum was computed at $\mathrm{T}=298 \mathrm{~K}, \lambda=532 \mathrm{~nm}$, and with a full width at half maximum (FWHM) of $5 \mathrm{~cm}^{-1}$. The experimental and computed spectra are compared in Figure 9. In Figure 9, the Raman spectrum have been split in four different spectral ranges in order to improve their visualization: (A) $0-1400 \mathrm{~cm}^{-1}$; (B) $1400-1600 \mathrm{~cm}^{-1}$; (C)
$1700-2000 \mathrm{~cm}^{-1}$; and (D) $2000-3000 \mathrm{~cm}^{-1}$. As can be appreciated the agreement is very satisfactory. Therefore, a normal mode analysis was carried out in order to assign the bands of the Raman spectrum. The experimental Raman band shifts and assignments performed by Lautie et $a L .^{7}$ are shown in Table 6, where the Raman shifts and assignments of the spectrum of free deltate ion, $\mathrm{C}_{3} \mathrm{O}_{3}^{2-}$, are also given. ${ }^{9-10}$ The band wavenumbers of the experimental and calculated spectra along with the corresponding calculated intensities and assignments are given in Table 7. Pictures of the atomic motions in the Raman active vibrational modes are depicted in Figure S.1 of the Supporting Information. The most important motion types of the atoms of the $\mathrm{C}_{3}$ carbon skeleton in the Raman active vibrational normal modes are shown in Figure 10.
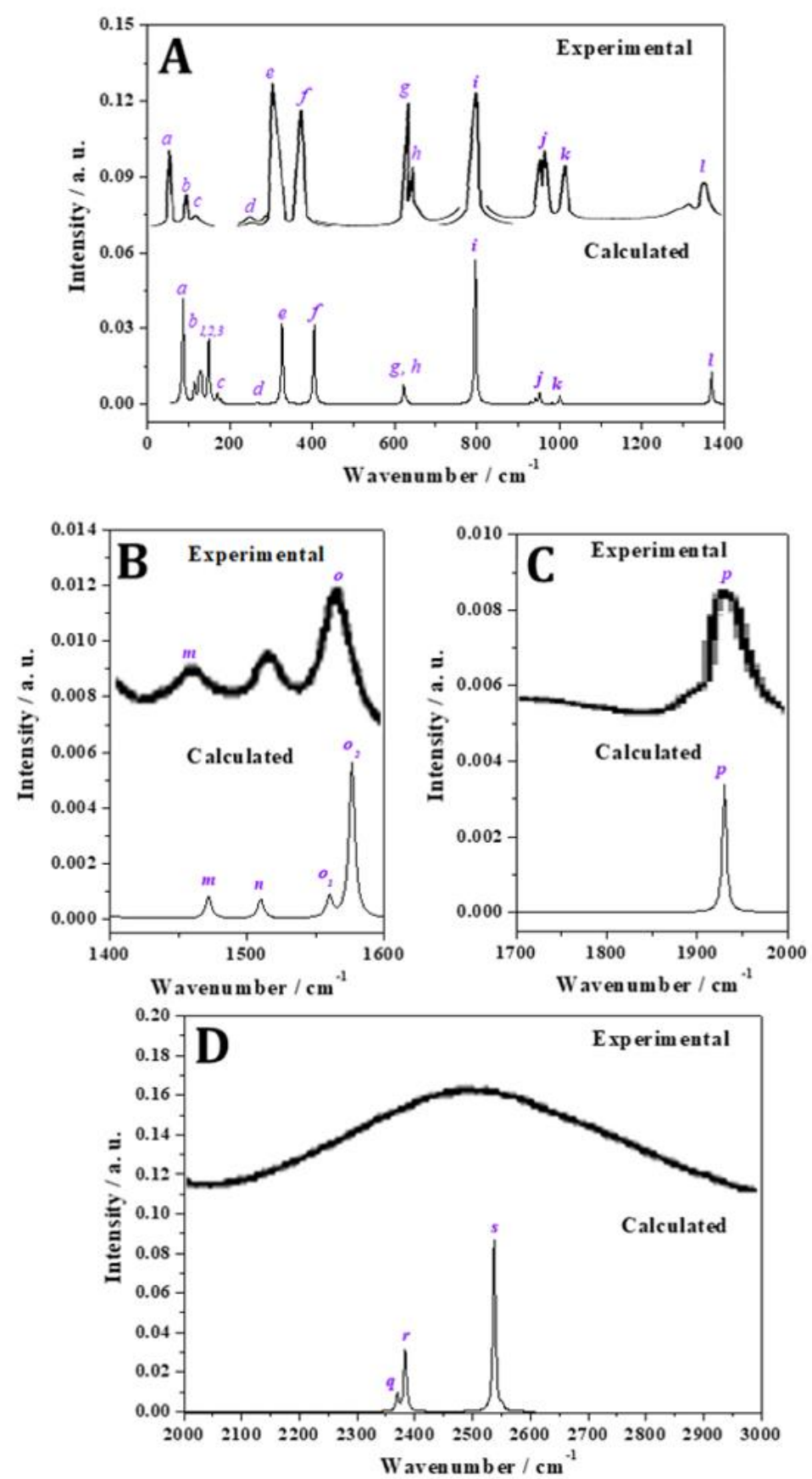

Figure 9. Experimental ${ }^{7}$ and calculated Raman spectra of the deltic acid in the spectral regions: (A) $0-1400 \mathrm{~cm}^{-1}$; $(\mathrm{B}) 1400-1600 \mathrm{~cm}^{-1}$; (C) $1700-2000 \mathrm{~cm}^{-1}$; (D) $2000-3000 \mathrm{~cm}^{-1}$. 
Table 6. Observed band wavenumbers $\left(\mathrm{cm}^{-1}\right)$ and assignments of the Raman spectrum of the deltic acid. ${ }^{7-10}$ The letters s, m and w stand for strong, medium and weak bands.

\begin{tabular}{ccccc}
\hline \multirow{2}{*}{ Band } & \multicolumn{2}{c}{ Solid deltic acid ${ }^{\mathbf{7 - 8}}$} & \multicolumn{2}{c}{ Free $\boldsymbol{C}_{\mathbf{3}} \boldsymbol{O}_{\mathbf{3}}^{\mathbf{2 -}} \mathbf{i o n}^{\mathbf{9 - 1 0}}$} \\
\cline { 2 - 5 } & Raman shift & Assignment & Raman shift & Assignment \\
\hline$a$ & 63 & - & - & - \\
$b$ & 109 & - & - & - \\
$c$ & 133 & - & - & - \\
$d$ & 269 & $v(O H \cdots O)$ & $258 / 236(\mathrm{~m})$ & $\delta^{\text {oop }}(\mathrm{CO})$ \\
$e$ & 315 & $\delta(C-O H)$ & $321 / 346(\mathrm{~m})$ & - \\
$f$ & 379 & $\gamma(C-O H)$ & - & - \\
$g$ & 641 & $\gamma(C=O)$ & - & - \\
$h$ & 653 & $\gamma(C=O)$ & $689 / 696(\mathrm{w})$ & $\delta_{\text {ring }}$ \\
$i$ & 799 & $\mathrm{Cycle}$ & $786 / 803(\mathrm{~s})$ & Ring breathing \\
$j$ & 957 & $\delta(C=O)$ & - & - \\
$k$ & 964 & $\delta(C=O)$ & $996 / 992(\mathrm{~m})$ & - \\
$l$ & 1350 & $v(C-O H)$ & - & - \\
$m$ & 1458 & $\delta(O-H)$ & $1432 / 1446(\mathrm{w})$ & $v(C C)$ \\
$n$ & 1569 & $\mathrm{Cycle}$ & - & - \\
$o$ & 1940 & $v(C=O)$ & $1818 / 1835(\mathrm{~m})$ & $v(\mathrm{CO})$ \\
\hline
\end{tabular}

Table 7. Experimental and calculated Raman band wavenumbers $\left(\mathrm{cm}^{-1}\right)$ of the Raman spectrum of the deltic acid, irreducible representations, calculated intensities and assignments. The meaning of the acronyms T, R, Pr, Di, Ro and Co is given in Figure 10.

\begin{tabular}{|c|c|c|c|c|c|}
\hline $\begin{array}{l}\text { Band } \\
\text { name }\end{array}$ & Exp..$^{7-8}$ & $\begin{array}{c}\text { Calc. } \\
\text { (This work) }\end{array}$ & $\begin{array}{l}\text { Irr. Rep. } \\
\left(D_{2 h}\right)\end{array}$ & $\begin{array}{l}\text { Int. } \\
\left(\AA^{4}\right)\end{array}$ & $\begin{array}{l}\begin{array}{l}\text { Assignment } \\
\text { (This work) }\end{array} \\
\end{array}$ \\
\hline$a$ & 63 & 86.1 & $A_{g}$ & 9.97 & $T(C=C)+T(O H)+\delta^{o o p}(C-C=O)$ \\
\hline \multirow[t]{3}{*}{$b$} & 109 & 127.4 & $B_{1 g}$ & 3.24 & $R(C=C)+T(O H)$ \\
\hline & & 131.0 & $A_{g}$ & 4.74 & $T\left(C_{3}\right)+\delta^{o o p}(C-C=O)$ \\
\hline & & 149.1 & $B_{3 g}$ & 13.15 & $\operatorname{Def}\left(\mathrm{C}_{3}\right)+T(\mathrm{OH})$ \\
\hline$c$ & 133 & 169.3 & $A_{g}$ & 2.66 & $T\left(C_{3}\right)+v(C=O)+\delta(C-H-O)$ \\
\hline$d$ & 269 & 268.1 & $B_{2 g}$ & 0.67 & $T\left(C_{3}\right)+\delta^{o o p}(C-C=O)+\delta^{o o p}(C-O-H)$ \\
\hline$e$ & 315 & 326.3 & $A_{g}$ & 62.19 & $T(\mathrm{OH})$ \\
\hline$f$ & 379 & 404.1 & $B_{1 g}$ & 64.57 & $T(O H)+\delta(C-C=O)$ \\
\hline$g$ & 641 & 622.0 & $B_{3 g}$ & 25.12 & $R(C=C)$ \\
\hline$h$ & 653 & 627.5 & $A_{g}$ & 9.48 & $\operatorname{Pr}\left(C_{3}\right)+\delta^{o o p}(C-C=O)$ \\
\hline$i$ & 799 & 796.5 & $A_{g}$ & 416.88 & $\mathrm{Di}\left(\mathrm{C}_{3}\right)+v(\mathrm{C}=\mathrm{O})+\mathrm{T}(\mathrm{OH})$ \\
\hline$j$ & 957 & 941.9 & $B_{3 g}$ & 19.94 & $R o\left(C_{3}\right)+\delta^{o o p}(C-O-H)$ \\
\hline$k$ & 964 & 952.2 & $B_{1 g}$ & 33.74 & “ \\
\hline$l$ & 1350 & 1370.6 & $A_{g}$ & 184.97 & $\delta(C-H-O)$ \\
\hline$m$ & 1458 & 1472.6 & $B_{3 g}$ & 12.68 & “ \\
\hline$n$ & - & 1510.4 & $B_{1 g}$ & 11.34 & “" \\
\hline \multirow[t]{2}{*}{$o$} & 1569 & 1559.8 & $B_{2 g}$ & 13.21 & “ \\
\hline & & 1576.2 & $A_{g}$ & 97.01 & “ \\
\hline$p$ & 1940 & 1930.2 & $A_{g}$ & 79.14 & $\mathrm{Co}\left(C_{3}\right)+v(C-O)+\delta(C-O-H)$ \\
\hline$q$ & - & 2369.4 & $B_{3 g}$ & 287.6 & $v(\mathrm{OH})$ \\
\hline$r$ & - & 2383.2 & $B_{1 g}$ & 1000.2 & “ \\
\hline$s$ & - & 2537.5 & $A_{g}$ & 3044.2 & “ \\
\hline
\end{tabular}



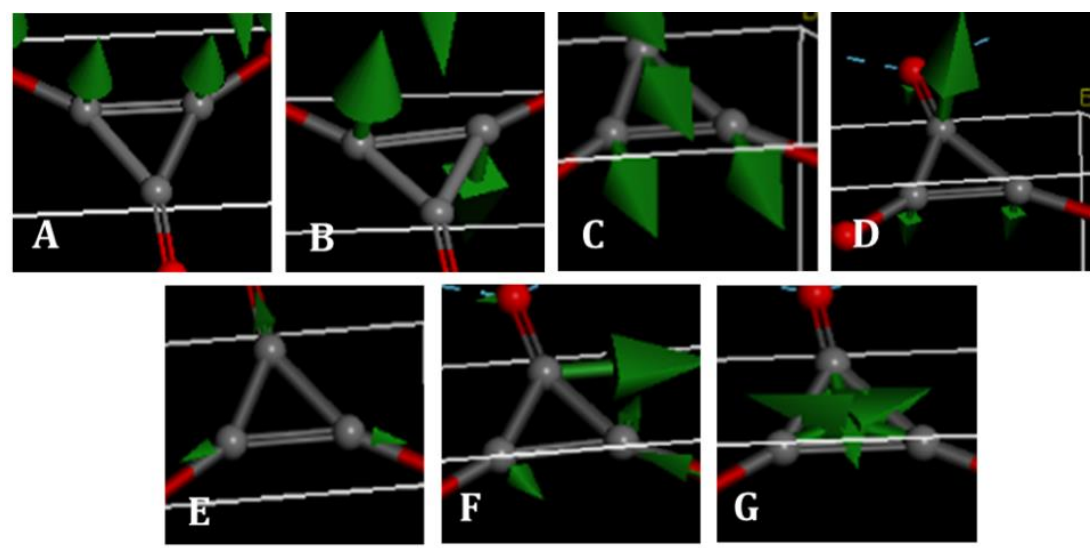

Figure 10. Motion types of the atoms of the $C_{3}$ carbon skeleton in the Raman active vibrational normal modes of the deltic acid: (A) Translation of the $\mathrm{C}=\mathrm{C}$ bond, $\mathrm{T}(\mathrm{C}=\mathrm{C})\left[86.1 \mathrm{~cm}^{-1}\right]$; $(\mathrm{B})$ Rotation of the $\mathrm{C}=\mathrm{C}$ bond, $\mathrm{R}(\mathrm{C}=\mathrm{C})\left[127.4,622.0 \mathrm{~cm}^{-1}\right]$; $(\mathrm{C}) \mathrm{Translation} \mathrm{T}^{\mathrm{T}}\left(\mathrm{C}_{3}\right)$ [131.0, 169.3, 268.1 cm $\left.\mathrm{cm}^{-1}\right]$; (D) Plane rotation, $\operatorname{Pr}\left(\mathrm{C}_{3}\right)\left[627.5 \mathrm{~cm}^{-1}\right]$; (E) Dilatation, $\operatorname{Di}\left(\mathrm{C}_{3}\right)\left[796.5 \mathrm{~cm}^{-1}\right]$; (F) In-plane rotation, $\operatorname{Ro}\left(C_{3}\right)\left[941.9,952.2 \mathrm{~cm}^{-1}\right]$; $(\mathrm{G})$ Contraction, $\operatorname{Co}\left(\mathrm{C}_{3}\right)\left[1930.2 \mathrm{~cm}^{-1}\right]$

As may be observed from Tables 6 and 7, the assignment of the Raman spectrum performed by Lautie et al. ${ }^{7}$ is incomplete and differs significantly from the present assignment. The empirical assignment derived from the spectrum of the free deltate ion is also incomplete and very different from that of Lautié et al. ${ }^{7}$ and that of the present work. The origin of the bands $(a)$ to $(c)$ and $(q)$ to $(s)$ is completely unknown

The lowest wavenumber band ( $a$ ) having an observed wavenumber of $63 \mathrm{~cm}^{-1}$ corresponds to the calculated one at 86 $\mathrm{cm}^{-1}$. This band is assigned to a combination of translations of the $\mathrm{C}=\mathrm{C}$ double bonds (see Fig. 10.A), translations of the hydroxyl $\mathrm{OH}^{-}$ions and out of plane $\mathrm{C}-\mathrm{C}=0$ bending vibrations. As observed in Table 7 and Figure 9.A, the next band $(b)$, placed in the experimental spectrum at $109 \mathrm{~cm}^{-1}$ contains in fact three different peaks corresponding to the calculated bands at 127,131 and $149 \mathrm{~cm}^{-1}$. The first of these bands is assigned to rotations of the $\mathrm{C}=\mathrm{C}$ double bonds (see Fig. 10.B) and translations of the hydroxyl ions. The second one is attributed to $\mathrm{C}_{3}$ carbon skeleton translations (Fig. 10.C) and $\mathrm{C}-\mathrm{C}=\mathrm{O}$ out of plane bending vibrations. Finally, the third one is ascribed to $\mathrm{C}_{3}$ carbon skeleton deformations and hydroxyl translations. The experimental band placed at $133 \mathrm{~cm}^{-1}(c)$ corresponds to the calculated band at $169 \mathrm{~cm}^{-1}$ and it is assigned to a combination of $\mathrm{C}_{3}$ ring translations, $\mathrm{C}=0$ stretching and $\mathrm{C}-$ $\mathrm{H}-\mathrm{O}$ bending vibrations. The three bands $(a)$ to $(c)$, were left without assignment in the experimental works.

The band at $269 \mathrm{~cm}^{-1}$ (d) was calculated to be at $268 \mathrm{~cm}^{-1}$ and was assigned by Lautié et al. ${ }^{7}$ to $\mathrm{OH} \cdots 0$ stretching vibrations. However, it should be attributed to $\mathrm{C}_{3}$ ring translations and $\mathrm{C}-$ $\mathrm{C}=\mathrm{O}$ and $\mathrm{C}-\mathrm{H}-\mathrm{O}$ out of plane bending vibrations. The pair of bands located at 315 and $379 \mathrm{~cm}^{-1},(e)$ and $(f)$, are very intense and correspond to the theoretical ones at 326 and 404 $\mathrm{cm}^{-1}$. The first one must be reassigned to hydroxyl ion translations and the second one to hydroxyl ion translations plus $\mathrm{C}-$ $\mathrm{C}=0$ bending vibrations. The bands at 641 and $653 \mathrm{~cm}^{-1},(g)$ and $(h)$, were calculated to be at 622 and $627 \mathrm{~cm}^{-1}$. The first of these bands should be ascribed to $\mathrm{C}=\mathrm{C}$ double bond rotations and the second one $\mathrm{C}_{3}$ ring plane rotations (see Fig. 10.D) and $\mathrm{C}-\mathrm{O}-\mathrm{H}$ bending vibrations.

The very intense band at $799 \mathrm{~cm}^{-1}(i)$ is very well reproduced by the theoretical calculations $\left(796 \mathrm{~cm}^{-1}\right)$. It must be assigned to a combination of $\mathrm{C}_{3}$ ring dilatations (Fig. 10.E), $\mathrm{C}=0$ bond stretching and hydroxyl translations. While the empirical assignment of this band attributes correctly this band to the $\mathrm{C}_{3}$ ring dilatations (called "cycle" by Lautié et al. ${ }^{7}$ or ring breathing vibrations by Junqueira et al. ${ }^{10}$ ) the remaining motions are neglected. However, as it can be seen in Figure S.1 of the Supporting Information, this motion has the smaller weight in the description of the corresponding normal mode, the weights of the other two motions being much larger. We prefer the use of the term dilatation instead of breathing, which is very commonly used, because we need to distinguish among ring dilatation and contraction (see Figure 10). The same term is frequently used for these two different types of motion.

The bands at 957 and $964 \mathrm{~cm}^{-1}$ (bands $(\mathrm{j})$ and $(\mathrm{k})$, respectively), are reproduced theoretically at 942 and $952 \mathrm{~cm}^{-1}$. Both bands must be reassigned to in-plane rotations of the $\mathrm{C}_{3}$ ring (Fig. 10.F) and $\mathrm{C}-\mathrm{O}-\mathrm{H}$ bending vibrations. The experimental bands located at 1350 and $1458 \mathrm{~cm}^{-1}$, (l) and $(m)$, are reproduced theoretically at 1371 and $1473 \mathrm{~cm}^{-1}$. The band $(n)$, whose existence is obvious in Figure 9.B, was apparently not seen by Lautié et al., ${ }^{7}$ and is situated at $1510 \mathrm{~cm}^{-1}$ in the theoretical spectrum. The band at $1569 \mathrm{~cm}^{-1}(o)$ is resolved into two components in the theoretical Raman spectrum placed at 1560 and $1576 \mathrm{~cm}^{-1}$. The last five bands must be assigned solely to $\mathrm{C}-\mathrm{H}-\mathrm{O}$ bending vibrations. The band at $1940 \mathrm{~cm}^{-1}$ is located at $1930 \mathrm{~cm}^{-1}$ in the theoretical spectrum. It is attributed to a combination of contractions of the $\mathrm{C}_{3}$ rings (Fig. 10.G), $\mathrm{C}-\mathrm{O}$ stretching and $\mathrm{C}-\mathrm{O}-\mathrm{H}$ bending vibrations.

Finally, it must be noted that the Raman spectrum bands in the long wavenumber region, $2000-3000 \mathrm{~cm}^{-1}$, are very broad. In fact, for this reason, Lautié et al., ${ }^{7}$ do not attempted to resolve the bands in this region. As it can be seen in Figure 9.D, the broad band located near $2500 \mathrm{~cm}^{-1}$ in the experimental spectrum is the result of the broadening and overlap of the three bands $(q),(r)$ and $s$ ) which appear in the theoretical spectrum at 2369,2383 and $2537 \mathrm{~cm}^{-1}$, respectively. These three bands are assigned to $\mathrm{OH}$ stretching vibrations. The reason for the large broadening of these bands is clearly the strong hydrogen bonding present in the crystal structure of deltic acid. ${ }^{6}$

\section{III.2.2. Squaric acid}

The experimental Raman spectrum of the squaric acid has been obtained in many occasions and may be found in several published articles. ${ }^{11-19}$ For example, this spectrum was recorded at 
$309 \mathrm{~K}$ by Baglin and Rose ${ }^{11}$ in 1970 with an estimated resolution of $\pm 4 \mathrm{~cm}^{-1}$. Similarly, Nakashima and Balkanski ${ }^{12}$ recorded the Raman spectrum of squaric acid at $77 \mathrm{~K}$ in 1976 with an improved resolution of about $\pm 2 \mathrm{~cm}^{-1}$. A more recent version was recorded at room temperature by Georgopoulos et al. ${ }^{13}$ in 2013 using a Bruker FT-Raman spectrometer having an estimated resolution of $\pm 2 \mathrm{~cm}^{-1}$. The experimental Raman band shifts from these works and the band assignments performed by Georgopoulos et al. ${ }^{13}$ are shown in Table 8 . In Table 8 the Raman shifts and assignments of the spectrum of the free squarate ion are also given. ${ }^{14-15}$ The theoretical Raman spectrum was computed at $\mathrm{T}=298 \mathrm{~K}, \lambda=532 \mathrm{~nm}$, and with a full width at half maximum (FWHM) of $20 \mathrm{~cm}^{-1}$. The experimental spectrum of Georgopoulos et al. $^{13}$ and the computed spectra are compared in Figure 11. As in the case of deltic acid, the agreement is very satisfactory and, therefore, a normal mode analysis was carried out in order to assign the bands in the Raman spectrum. The band wavenumbers of the experimental and calculated spectra along with the corresponding calculated intensities and assignments are given in Table 9. Images of the atomic motions in the Raman active vibrational modes are shown in Figure S.2 of the Supporting Information. The motion types of the atoms of the $\mathrm{C}_{4}$ carbon skeleton in the Raman active vibrational normal modes are shown in Figure 12.

As shown in Table 9, the band with the lowest wavenumber $(\alpha)$, at $85 \mathrm{~cm}^{-1}$, really corresponds to two contributing bands which are very close and are calculated theoretically to be at 89 and 90 $\mathrm{cm}^{-1}$. These two bands must be assigned to translations of the squaric acid molecules along the $a$ and $b$ directions, respectively. The second band which was found at $153 \mathrm{~cm}^{-1}$ in the works by Baglin and Rose ${ }^{11}$ and Georgopoulos et al. ${ }^{13}$ was shown by Nakashima and Balkanski ${ }^{12}$ to be resolved into three different contributions at 153,158 and $164 \mathrm{~cm}^{-1}$. This feature is in complete agreement with the findings from the theoretical spectrum, since three near bands at 152,163 and $172 \mathrm{~cm}^{-1}$ were obtained. The theoretical methods allow going far beyond of predicting this feature since permit to assign them. The first one must be attributed to out-of-plane $\mathrm{C}-\mathrm{O}-\mathrm{H}$ bending vibrations and hydroxyl translations, the second one to out of plane $\mathrm{C}-\mathrm{O}-\mathrm{H}$ and $\mathrm{C}-\mathrm{C}=\mathrm{O}$ bending vibrations and the last one to out-of-plane $\mathrm{C}-\mathrm{C}=\mathrm{O}$ bending vibrations. The weak band (b) located at $230 \mathrm{~cm}^{-1}$ found by Baglin and Rose ${ }^{11}$ was not encountered by Nakashima and Balkanski ${ }^{12}$ and Georgopoulos et al. ${ }^{13}$ and it is absent in the theoretical spectrum. It is identified as a combination of the $(\alpha)$ and $(a)$ bands as indicated in the assignment column of Table 9 .

The band at $241 \mathrm{~cm}^{-1}$ is calculated to be at $260 \mathrm{~cm}^{-1}$ and it must be assigned to a combination of translations of the four membered carbon rings plus $\mathrm{C}=0$ and $\mathrm{C}-\mathrm{O}$ bond rotations and hydroxyl translations. The band at $274 \mathrm{~cm}^{-1}$ corresponds to the computed one at $272 \mathrm{~cm}^{-1}$ which is ascribed to hydroxyl translations, $\mathrm{OH}$ stretching and $\mathrm{C}-\mathrm{O}-\mathrm{H}$ bending vibrations. This is the first band for which we could try to assign the band empirically from the weak band of the squarate ion at $294 \mathrm{~cm}^{-1}$. However, this band was assigned to out of plane $\mathrm{CO}$ bending vbrations. This vibrational motion associated to this assignment is completely different to the combination of atomic motions found in the present work. The band found at $308 \mathrm{~cm}^{-1}$ is reproduced theoretically at $306 \mathrm{~cm}^{-1}$ and should be assigned to hydroxyl translations and $\mathrm{C}-\mathrm{C}=\mathrm{O}$ bending vibrations. Band $(f)$, at $383 \mathrm{~cm}^{-1}$, corresponds to the computed one at $415 \mathrm{~cm}^{-1}$ is assigned to $\mathrm{C}-\mathrm{O}-\mathrm{H}$ and $\mathrm{C}-\mathrm{C}=\mathrm{O}$ bending vibrations coupled with $\mathrm{OH}$ stretching vibrations. The weak band $(\mathrm{g})$ at $445 \mathrm{~cm}^{-1}$, absent in the computed spectrum, is a combination band arising from bands $(a)$ and $(e)$.

The experimental band at $626 \mathrm{~cm}^{-1}$ is, as some previous bands, shown to contain two contributions which were theoretically found at 626 and $629 \mathrm{~cm}^{-1}$. These two bands having similar intensities in the calculated spectrum are attributed to rotations of the $\mathrm{C}_{4}$ carbon ring plane (see Fig. 12.B). The next three experimental bands, at 639,735 and $858 \mathrm{~cm}^{-1}$ are reproduced theoretically at 620,721 and $852 \mathrm{~cm}^{-1}$, respectively. These three bands must be assigned to a combination of $\mathrm{C}=\mathrm{O}$ and $\mathrm{C}-\mathrm{O}$ bond stretching, $\mathrm{C}-\mathrm{O}-\mathrm{H}$ bending vibrations and three different atomic motions of the $\mathrm{C}_{4}$ carbon skeleton: $\mathrm{Rh}\left(\mathrm{C}_{4}\right), \operatorname{Co}\left(\mathrm{C}_{4}\right)$ and $\operatorname{Ro}\left(C_{4}\right)$ (see Figs. 12.C, D, E). The first one is the square to rhombus deformation, the second one is the ring contraction and the last one is the $\mathrm{C}_{4}$ ring rotation in the plane. With the exception of the assignment of the second band (assigned in the experimental works as a ring breathing mode), the other bands must be reassigned and even for the second one, the most part of the vibrational contributions are neglected in the empirical assignment. The bands at 1053, 1062 and $1174 \mathrm{~cm}^{-1}$ correspond to the calculated bands at 1037,1047 and $1141 \mathrm{~cm}^{-1}$. Both bands are attributed to square to trapezium deformations, $\mathrm{C}-\mathrm{O}-\mathrm{H}$ bending vibrations and, for the first two bands, $\mathrm{C}-$ $\mathrm{O}$ bond stretching vibrations. Again, the empirical assignment should be corrected.

The band $(o)$ at $1251 \mathrm{~cm}^{-1}$ is clearly an overtone band of the (h) band $\left(2 v_{1}\right.$ where $\left.v_{1}=626 \mathrm{~cm}^{-1}\right)$. This fact has not been noticed in any of the previous spectroscopic works. The bands at 1307 and 1362 and $1514 \mathrm{~cm}^{-1}$ are reproduced theoretically at 1324, 1331 and $1551 \mathrm{~cm}^{-1}$. These bands are assigned to $\mathrm{C}-$ $\mathrm{O}-\mathrm{H}$ bending vibrations. The band at $1385 \mathrm{~cm}^{-1}$, absent in the computed spectrum, is recognized as a combination of $(i)$ and $(j)$ bands. The band at $1532 \mathrm{~cm}^{-1}$ is reproduced at $1570 \mathrm{~cm}^{-1}$ and has the same assignment that the $(j)$ band, which as mentioned in the previous paragraph is mainly ascribed to square to rhombus deformations, $\operatorname{Rh}\left(\mathrm{C}_{4}\right)$. The bands $(u)$ and $(v)$, at 1630 and $1677 \mathrm{~cm}^{-1}$, are combination bands of the $(n)$ and $(g)$ bands and $(l)$ and $(h)$ bands, respectively. Finally, the band $1829 \mathrm{~cm}^{-1}$ is reproduced at $1784 \mathrm{~cm}^{-1}$ and assigned to a combination of ring contractions and $\mathrm{C}=\mathrm{O}, \mathrm{C}-\mathrm{O}$ and $\mathrm{O}-\mathrm{H}$ bond stretching vibrations.

While Baglin and Rose ${ }^{21}$ identified a low wavenumber combination band in the infrared spectrum of squaric acid at $346 \mathrm{~cm}^{-1}$ and another in the Raman spectrum at $1677 \mathrm{~cm}^{-1}$ (band $(v)$ see above), the theoretical calculations have allowed to recognize one overtone band $(o)$ and four additional combination bands, $(b),(g),(r)$ and $(u)$, in the Raman spectrum. The situation is similar to that found in the Raman spectrum of natroxalate ${ }^{24}$ and oxammite ${ }^{25}$ minerals in which a large number of bands of these types were identified. To conclude this section is very important to note that in the theoretical Raman spectrum there are two additional bands at 2047 and $2054 \mathrm{~cm}^{-1}$ which are assigned to $\mathrm{OH}$ stretching vibrations. These bands must obviously exist in the experimental spectrum but, as in the case of the deltic acid, they must be relatively weak or too broad to be resolved experimentally. 
Table 8. Observed band wavenumbers $\left(\mathrm{cm}^{-1}\right)$ and assignments of the Raman spectrum of the squaric acid. ${ }^{11-15}$ The letters vs, $\mathrm{s}$, m, w and vw stand for very strong, strong, medium, weak and very weak bands.

\begin{tabular}{|c|c|c|c|c|c|c|}
\hline \multirow[b]{2}{*}{$\begin{array}{l}\text { Band } \\
\text { name }\end{array}$} & \multicolumn{4}{|c|}{ Solid squaric acid ${ }^{11-13}$} & \multicolumn{2}{|c|}{ Free $\mathrm{C}_{4} \mathrm{O}_{4}^{2-}$ ion $^{14-15}$} \\
\hline & $\begin{array}{c}\text { Raman shift }^{11} \\
(309 \mathrm{~K})\end{array}$ & $\begin{array}{c}\text { Raman shift }^{12} \\
(77 \mathrm{~K})\end{array}$ & $\begin{array}{c}\text { Raman shift }^{13} \\
(298 \mathrm{~K})\end{array}$ & Assignment ${ }^{13}$ & $\begin{array}{c}\text { Raman } \\
\text { shift }\end{array}$ & Assignment \\
\hline \multirow{2}{*}{$\alpha$} & \multirow{2}{*}{85} & 89 & - & - & \multirow{2}{*}{$99(w)$} & \multirow[b]{2}{*}{ - } \\
\hline & & 90 & - & - & & \\
\hline \multirow[t]{3}{*}{$a$} & \multirow[t]{3}{*}{153} & 153.5 & - & - & - & - \\
\hline & & 158.5 & - & - & - & - \\
\hline & & 164 & - & - & - & - \\
\hline$b$ & 230 & - & - & - & - & - \\
\hline$c$ & 241 & - & - & - & $259(\mathrm{~s})$ & $\delta_{\text {oop }}(\mathrm{CO})$ \\
\hline$d$ & 274 & 245 & - & - & $294(w)$ & $\delta(\mathrm{CO})$ \\
\hline$e$ & 308 & 307 & - & - & - & - \\
\hline$f$ & 383 & 383 & $380(\mathrm{~s})$ & $\delta(\mathrm{CO})$ & $350(\mathrm{~m})$ & $v(\mathrm{CO})$ \\
\hline$g$ & 445 & - & - & - & - & - \\
\hline \multirow[t]{2}{*}{$h$} & \multirow[t]{2}{*}{626} & 626 & - & - & \multirow{2}{*}{$662(\mathrm{vw})$} & \multirow{2}{*}{$\delta_{\text {oop }}(\mathrm{CO})$} \\
\hline & & 629 & - & - & & \\
\hline$i$ & 639 & 635 & $635(\mathrm{~s})$ & Ring torsion & $647(\mathrm{~s})$ & $v(\mathrm{CC})$ \\
\hline$j$ & 735 & 729 & $726(\mathrm{~s})$ & Ring breathing & $723(\mathrm{~s})$ & Ring breathing \\
\hline$k$ & 858 & 856 & - & - & 844 & $v(\mathrm{CC})+v(\mathrm{CO})$ \\
\hline$l$ & 1053 & 1051 & $1049(w)$ & $v(\mathrm{CC})$ & \multirow{2}{*}{$1090(\mathrm{~s})$} & \multirow{2}{*}{$v(\mathrm{CC})$} \\
\hline$m$ & 1062 & - & - & - & & \\
\hline$n$ & 1174 & 1177 & $1172(\mathrm{~m})$ & $v(\mathrm{CC})$ & 1123 (vs) & $v(\mathrm{CC})$ \\
\hline$o$ & 1251 & 1250 & $1297(w)$ & $v(\mathrm{CO})$ & - & - \\
\hline$p$ & 1307 & - & - & - & - & - \\
\hline$q$ & 1362 & - & - & - & - & - \\
\hline$r$ & 1385 & - & - & - & - & - \\
\hline$s$ & 1514 & 1510 & $1510(w)$ & $v(\mathrm{CO})$ & \multirow{2}{*}{$1530(\mathrm{vs})$} & \multirow{2}{*}{$v(\mathrm{CO})$} \\
\hline$t$ & 1532 & - & $1579(\mathrm{w})$ & $v(\mathrm{CO})$ & & \\
\hline$u$ & 1630 & - & $1616(w)$ & $v(\mathrm{CO})$ & $1593(\mathrm{~s})$ & $v(\mathrm{CO})$ \\
\hline$v$ & 1677 & - & - & $1380+308=1688^{21}$ & - & - \\
\hline$w$ & 1829 & - & $1824(\mathrm{vw})$ & $v(\mathrm{CO})$ & $1794(w)$ & $v(\mathrm{CC})+v(\mathrm{CO})$ \\
\hline
\end{tabular}

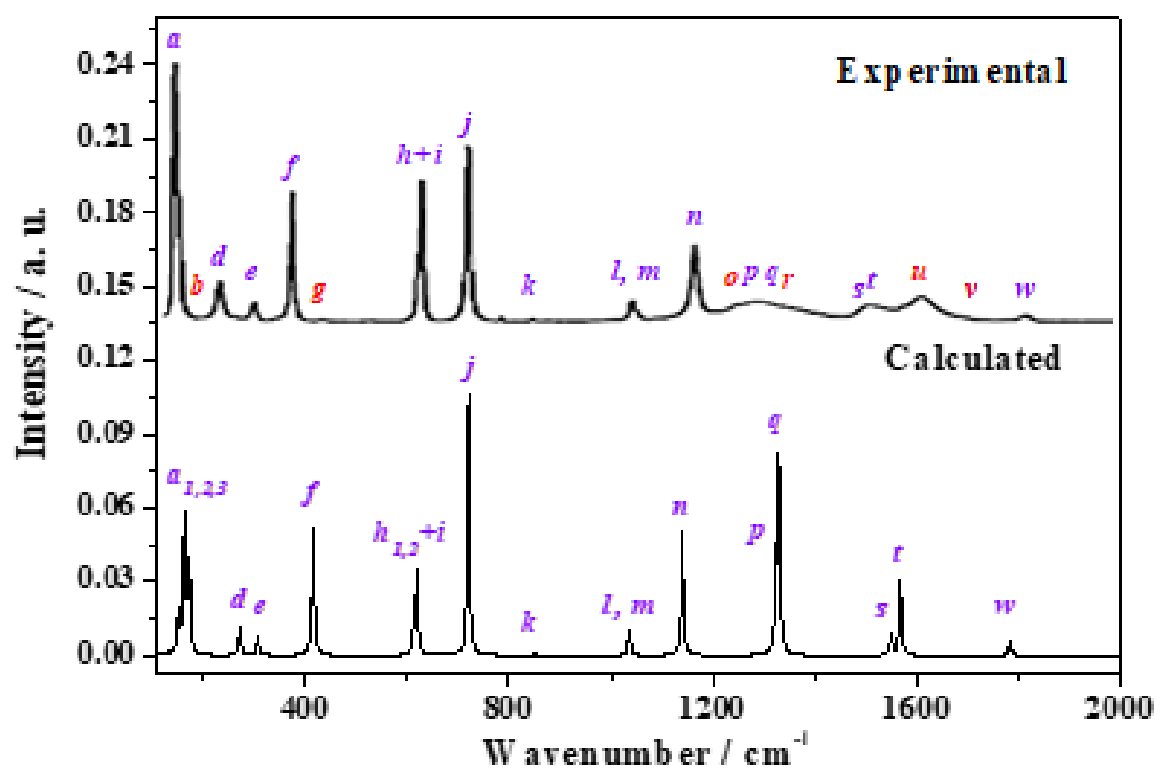

Figure 11. Experimental ${ }^{13}$ and calculated Raman spectra of the squaric acid. The overtone band $(o)$ and the combination bands $(b),(g),(r)$, $(u)$ and $(v)$ are highlighted in red. 
Table 9. Observed and calculated Raman band wavenumbers $\left(\mathrm{cm}^{-1}\right)$ in the Raman spectrum of the squaric acid, irreducible representations, calculated intensities and assignments. The meaning of the acronyms T, Pr, Rh, Co, Ro and Tp is given in Figure 12.

\begin{tabular}{|c|c|c|c|c|c|c|c|}
\hline $\begin{array}{l}\text { Band } \\
\text { name }\end{array}$ & Exp. ${ }^{11}$ & Exp. ${ }^{12}$ & Exp. ${ }^{13}$ & $\begin{array}{c}\text { Calc. } \\
\text { (This work) } \\
\end{array}$ & $\begin{array}{c}\text { Irr. Rep. } \\
\left(C_{2 h}\right)\end{array}$ & $\begin{array}{l}\text { Int. } \\
\left(\AA^{4}\right)\end{array}$ & $\begin{array}{l}\text { Assignment } \\
\text { (This work) }\end{array}$ \\
\hline \multirow[t]{2}{*}{$\alpha$} & 85 & 89 & - & 76.4 & $\mathrm{Ag}$ & 0.40 & $T^{b}\left(\mathrm{H}_{2} \mathrm{C}_{4} \mathrm{O}_{4}\right)$ \\
\hline & & 90 & - & 99.2 & $\mathrm{Ag}$ & 0.41 & $\mathrm{~T}^{a}\left(\mathrm{H}_{2} \mathrm{C}_{4} \mathrm{O}_{4}\right)$ \\
\hline \multirow[t]{3}{*}{$a$} & 153 & 153.5 & - & 151.9 & $\mathrm{Bg}$ & 10.26 & $\delta^{o o p}\left(C-O^{\prime}-H^{\prime}\right)+T\left(O H^{-}\right)$ \\
\hline & & 158.5 & - & 162.8 & $\mathrm{Bg}$ & 40.02 & $\delta^{o o p}(C-O-H)+\delta^{o o p}(C-C=O)$ \\
\hline & & 164 & - & 171.5 & $\mathrm{Bg}$ & 28.00 & $\delta^{o o p}(C-C=O)$ \\
\hline$b$ & 230 & - & - & - & - & - & $v_{1}+v_{2}=238\left(v_{1}=153, v_{2}=85\right)$ \\
\hline$c$ & 241 & - & - & 260.1 & $\mathrm{Ag}$ & 0.23 & $\mathrm{~T}\left(C_{4}\right)+R(C=O)+R(C-O)+T\left(O H^{-}\right)$ \\
\hline$d$ & 274 & 245 & - & 272.2 & $\mathrm{Ag}$ & 20.22 & $T\left(O H^{-}\right)+v\left(O^{\prime}-H^{\prime}\right)+\delta\left(C-O^{\prime}-H^{\prime}\right)$ \\
\hline$e$ & 308 & 307 & - & 306.9 & $\mathrm{Ag}$ & 15.97 & $T\left(O H^{-}\right)+\delta(C-C=O)$ \\
\hline$f$ & 383 & 383 & - & 415.2 & $\mathrm{Ag}$ & 162.35 & $\delta(C-C=O)+v(O-H)+\delta(C-O-H)$ \\
\hline$g$ & 445 & - & - & - & - & - & $v_{1}+v_{2}=461\left(v_{1}=308, v_{2}=153\right)$ \\
\hline \multirow[t]{2}{*}{$h$} & 626 & 626 & - & 613.2 & $\mathrm{Bg}$ & 29.70 & $\operatorname{Pr}\left(C_{4}\right)$ \\
\hline & & 629 & - & 614.6 & $\mathrm{Bg}$ & 25.60 & “ \\
\hline$i$ & 639 & 635 & $635(\mathrm{~s})$ & 620.1 & $\mathrm{Ag}$ & 176.62 & $R h\left(C_{4}\right)+v(C=O)+v(C-O)+\delta(C-O-H)$ \\
\hline$j$ & 735 & 729 & $726(s)$ & 721.1 & $\mathrm{Ag}$ & 679.47 & $C o\left(C_{4}\right)+v(C=O)+v(C-O)+\delta(C-O-H)$ \\
\hline$k$ & 858 & 856 & - & 851.6 & $\mathrm{Ag}$ & 6.53 & $R o\left(C_{4}\right)+v(C=O)+v(C-O)+\delta(C-O-H)$ \\
\hline$l$ & 1053 & 1051 & $1049(w)$ & 1036.8 & $\mathrm{Ag}$ & 102.86 & $T p\left(C_{4}\right)+v(C-O)+\delta(C-O-H)$ \\
\hline$m$ & 1062 & - & - & 1047.5 & $\mathrm{Ag}$ & 7.54 & “ \\
\hline$n$ & 1174 & 1177 & $1172(\mathrm{~m})$ & 1140.8 & $\mathrm{Ag}$ & 593.75 & $T p\left(C_{4}\right)+\delta(C-O-H)$ \\
\hline$o$ & 1251 & 1250 & $1297(w)$ & - & - & - & $2 v_{1}=1252\left(v_{1}=626\right)$ \\
\hline$p$ & 1307 & - & - & 1324.4 & $\mathrm{Ag}$ & 507.87 & $\delta(C-O-H)$ \\
\hline$q$ & 1362 & - & - & 1331.2 & $\mathrm{Ag}$ & 1077.13 & “ \\
\hline$r$ & 1385 & - & - & & - & - & $v_{1}+v_{2}=1374\left(v_{1}=735, v_{2}=639\right)$ \\
\hline$s$ & 1514 & 1510 & $1510(w)$ & 1551.0 & $\mathrm{Ag}$ & 151.97 & $\delta(C-O-H)$ \\
\hline$t$ & 1532 & - & $1579(w)$ & 1569.9 & $\mathrm{Ag}$ & 522.81 & $R h\left(C_{4}\right)+v(C=O)+v(C-O)+\delta(C-O-H)$ \\
\hline$u$ & 1630 & - & $1616(w)$ & - & - & - & $v_{1}+v_{2}=1619\left(v_{1}=1174, v_{2}=445\right)$ \\
\hline$v$ & 1677 & - & - & - & - & - & $v_{1}+v_{2}=1679\left(v_{1}=1053, v_{2}=626\right)$ \\
\hline$w$ & 1829 & - & 1824(vw) & 1783.8 & $\mathrm{Ag}$ & 110.04 & $\mathrm{Co}\left(C_{4}\right)+v(C=O)+v(C-O)+v(O-H)$ \\
\hline
\end{tabular}
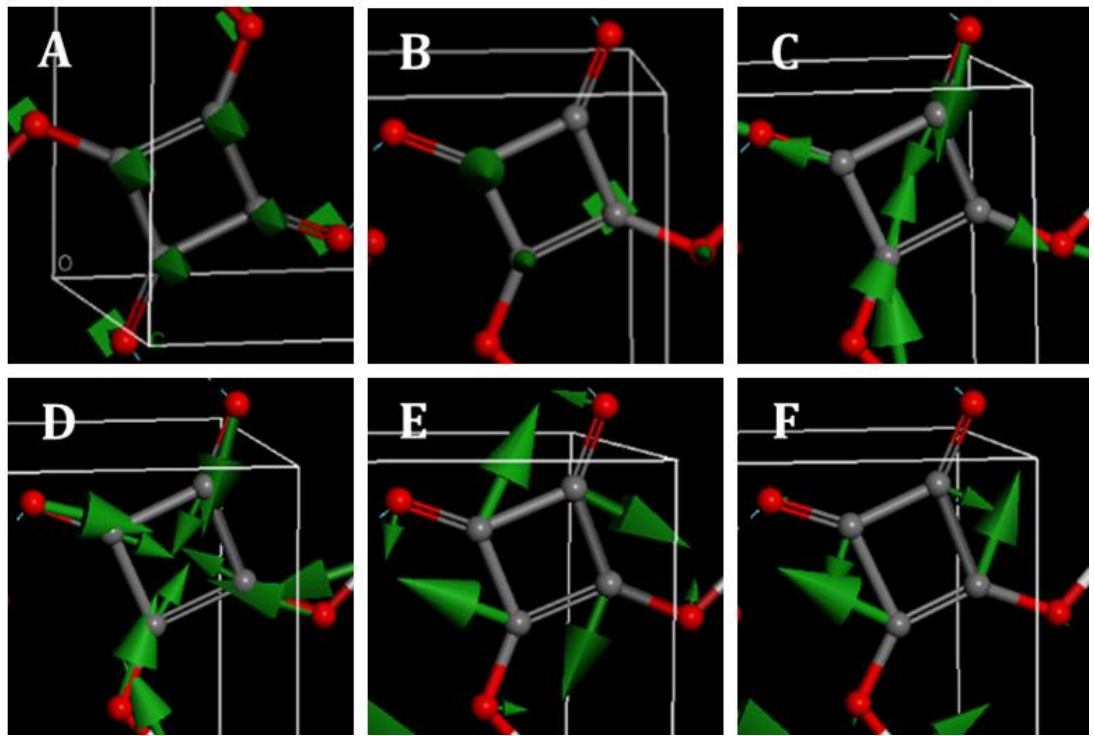

Figure 12. Motion types of the atoms of the $\mathrm{C}_{4}$ carbon skeleton in the Raman active vibrational normal modes of the squaric acid: (A) Translation, $\mathrm{T}\left(\mathrm{C}_{4}\right)\left[260.1 \mathrm{~cm}^{-1}\right]$; (B) Plane rotation, $\operatorname{Pr}\left(\mathrm{C}_{4}\right)\left[613.2,614.6 \mathrm{~cm}^{-1}\right]$; (C) Square to rhombus deformation, $\mathrm{Rh}\left(\mathrm{C}_{4}\right)[620.1$, $\left.1569.9 \mathrm{~cm}^{-1}\right]$; (D) Contraction, $\mathrm{Co}\left(\mathrm{C}_{4}\right)$ [721.1, $\left.1783.8 \mathrm{~cm}^{-1}\right]$; (E) In-plane rotation, $\mathrm{Ro}\left(\mathrm{C}_{4}\right)$ [851.6 $\left.9 \mathrm{~cm}^{-1}\right]$; (F) Square to trapezium deformation, $\operatorname{Tp}\left(\mathrm{C}_{4}\right)\left[1036.8,1047.5,1140.8 \mathrm{~cm}^{-1}\right]$.

\section{III.2.3. Croconic acid}

The experimental Raman spectrum of the croconic acid used as reference in this work, was recorded very recently by MilanGarces et al. ${ }^{20}$ using a Bruker Senterra Raman spectrometer coupled to an Olympus microscope. The excitation source used was the $632.8 \mathrm{~nm}$ output of a He-Ne laser. The spectral resolution was $3-5 \mathrm{~cm}^{-1}$. The measured experimental Raman band shifts and the band assignments given by these authors are listed in Table 10 where the Raman shifts and assignments of the spectrum of the free croconate ion ${ }^{21-23}$ are also given. The theoretical Raman spectrum was computed at $\mathrm{T}=298 \mathrm{~K}, \lambda=532 \mathrm{~nm}$, 
and with a FWHM of $10 \mathrm{~cm}^{-1}$. The experimental spectrum and the computed spectra are compared in Figure 13. Again, the agreement between these spectra is very good. The band wavenumbers of the experimental and calculated spectra along with the corresponding calculated intensities and the assignments performed in this work are given in Table 11. The atomic motions in the Raman active vibrational modes of croconic acid are displayed in Figure S.3 of the Supporting Information. The motion types of the atoms of the $\mathrm{C}_{5}$ carbon skeleton in the Raman active vibrational normal modes are shown in Figure 14.

The band with the lowest wavenumber $(a)$ in the Raman spectrum of the croconic acid is calculated to be at $121 \mathrm{~cm}^{-1}$. It must be assigned to translations of the $\mathrm{C}_{5}$ ring, $\mathrm{C}=\mathrm{O}$ bond and hydroxyl ions. Similarly, the bands $(b)$ to $(f)$ are found in the theoretical Raman spectrum at 151, 243, 383, 407 and $506 \mathrm{~cm}^{-1}$ and are assigned as detailed in Table 11. These low wavenumber bands, $(a)$ to $(f)$, do not appear in the experimental work of Milan-Garces et al, ${ }^{20}$ their analysis beginning at the band $(g)$. The band $(g)$ is observed at $521 \mathrm{~cm}^{-1}$ and calculated at $522 \mathrm{~cm}^{-1}$. It must be assigned to a combination of deformations of the five membered rings, $\mathrm{C}-\mathrm{C}$ bond stretching, and $\mathrm{C}-\mathrm{C}=\mathrm{O}$ bending vibrations and hydroxyl translations. The bands placed at 534 and $553 \mathrm{~cm}^{-1}$ are reproduced theoretically at 543 and $547 \mathrm{~cm}^{-1}$ and are ascribed to $C_{5}$ ring elongations (see Fig. 14.C), $\mathrm{C}=0$ bond and hydroxyl translations. The band at $565 \mathrm{~cm}^{-1}$ is calculated to be at $561 \mathrm{~cm}^{-1}$ and attributed to a combination of $\mathrm{C}_{5}$ ring widenings (see Fig. 14.D), $\mathrm{C}=0$ bond and hydroxyl translations. The peak at $634 \mathrm{~cm}^{-1}$ is found at $631 \mathrm{~cm}^{-1}$ and assigned to ring contractions (see Fig. 14.K), $\mathrm{C}=\mathrm{O}$ and $\mathrm{C}-\mathrm{O}$ bond stretching and $\mathrm{C}-\mathrm{O}-\mathrm{H}$ bending vibrations. While this band was correctly assigned to ring breathing vibrations in the experimental works, this description is very incomplete since it neglects the remaining vibrational contributions to the corresponding mode. The bands at 731 and 806 $\mathrm{cm}^{-1}$ are found at 734 and $783 \mathrm{~cm}^{-1}$. Both are assigned to ring bending vibrations (see Fig. 14.E).

Table 10. Observed band wavenumbers $\left(\mathrm{cm}^{-1}\right)$ and assignments of the Raman spectrum of the croconic acid..$^{20-23}$ The letters $\mathrm{s}$, $\mathrm{m}$ and $\mathrm{w}$ and vw stand for strong, medium, weak and very weak bands.

\begin{tabular}{|c|c|c|c|c|}
\hline \multirow{2}{*}{$\begin{array}{l}\text { Band } \\
\text { name }\end{array}$} & \multicolumn{2}{|c|}{ Solid croconic acid a $^{20}$} & \multicolumn{2}{|c|}{ Free $\mathrm{C}_{5} \mathrm{O}_{5}^{2-}$ ion $^{21-23}$} \\
\hline & Raman shift & Assignment & Raman shift & Assignment \\
\hline$d$ & - & - & $360(\mathrm{vw})$ & $\delta(\mathrm{CO})$ \\
\hline$g$ & 521 & - & - & - \\
\hline$h$ & 534 & $\delta_{\text {oop }}(\mathrm{CO})$ & $537(\mathrm{~m})$ & $\delta_{\text {oop }}(\mathrm{CO})$ \\
\hline$i$ & 553 & $\delta_{\text {ring }}$ & $556(\mathrm{~s})$ & $\delta_{\text {ring }}$ \\
\hline$j$ & 565 & - & - & - \\
\hline$k$ & 634 & Ring breathing & $637(\mathrm{~m})$ & Ring breathing \\
\hline$l$ & 731 & $\begin{array}{c}\mathrm{C}_{2}-\mathrm{C}_{3}-\mathrm{C}_{4} \text { out of } \\
\text { plane ring twisting }\end{array}$ & - & 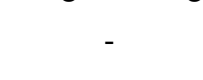 \\
\hline$m$ & 806 & $\delta(\mathrm{CO})$ & - & - \\
\hline$n$ & 1074 & $v(\mathrm{CC})$ & - & - \\
\hline$o$ & 1082 & $v(\mathrm{CC})$ & - & - \\
\hline$p$ & 1150 & $v(\mathrm{CC})$ & - & - \\
\hline$q$ & 1169 & $v(\mathrm{CC})$ & - & - \\
\hline$r$ & 1236 & $v(\mathrm{CC})$ & $1246(\mathrm{~m})$ & $v(\mathrm{CC})$ \\
\hline$s$ & 1302 & - & - & - \\
\hline$t$ & 1384 & - & - & - \\
\hline$v$ & 1522 & $v(\mathrm{CC})+v(\mathrm{CO})$ & $1591(\mathrm{~s})$ & $v(\mathrm{CO})$ \\
\hline$w$ & 1652 & $v(\mathrm{CC})+v(\mathrm{CO})$ & - & - \\
\hline$x$ & 1722 & $v(\mathrm{CO})$ & $1721(w)$ & $v(\mathrm{CO})$ \\
\hline$y$ & 1757 & $v(\mathrm{CO})$ & - & - \\
\hline
\end{tabular}

The three bands found experimentally at 1074, 1082 and 1150 $\mathrm{cm}^{-1}$ were found theoretically at 1063,1081 and $1152 \mathrm{~cm}^{-1}$. The three bands are assigned to $\mathrm{C}-\mathrm{O}-\mathrm{H}$ bending vibrations. The band at $1169 \mathrm{~cm}^{-1}$ is shown to be composed of two bands which were determined at 1165 and $1171 \mathrm{~cm}^{-1}$. These bands are assigned to a combination of $\mathrm{C}_{2}-\mathrm{C}_{3}$ and $\mathrm{C}_{4}-\mathrm{C}_{5}$ bond elongation, $\mathrm{C}_{3}-\mathrm{C}_{4}$ bond shortening and $\mathrm{C}-\mathrm{O}-\mathrm{H}$ bending vibrations (See Fig. 14.F). The band at $1236 \mathrm{~cm}^{-1}$ also contains two contributing bands which were determined at 1245 and $1257 \mathrm{~cm}^{-1}$ which are attributed to a combination of $\mathrm{C}_{5}-\mathrm{C}_{1}$ bond shortening and $\mathrm{C}-\mathrm{O}-\mathrm{H}$ bending vibrations (See Fig. 14.G). The bands $(s),(t)$ and $(v)$ at 1302,1384 and $1522 \mathrm{~cm}^{-1}$ are reproduced at $1310,(1378,1397)$ and $1517 \mathrm{~cm}^{-1}$ and are assigned to $\mathrm{C}-\mathrm{O}-\mathrm{H}$ bending vibrations. A band corresponding to the theoretical band $(u)$ at $1477 \mathrm{~cm}^{-1}$ was not reported by Milan-Garces et $a l .{ }^{20}$ although it is clearly observed in the experimental spectrum given in Figure 13. The band $(w)$ at $1652 \mathrm{~cm}^{-1}$ contains three contributing bands whose theoretical wavenumbers are 1552,1564 and $1576 \mathrm{~cm}^{-1}$. The first is assigned to $\mathrm{C}_{3}-\mathrm{C}_{4}$ bond shortening, $\mathrm{C}_{4}-\mathrm{C}_{5}$ bond rotation, $\mathrm{C}=$ $\mathrm{O}$ bond stretching and $\mathrm{C}-\mathrm{O}-\mathrm{H}$ bending vibrations and the other two ones to $\mathrm{C}_{3}-\mathrm{C}_{4}$ bond elongation, the approach of the $\mathrm{C}_{2}$ and $\mathrm{C}_{5}$ non bonded carbon atoms, $\mathrm{C}=0$ bond stretching and $\mathrm{C}-\mathrm{O}-\mathrm{H}$ bending vibrations. The band at $1722 \mathrm{~cm}^{-1}$ is found at $1632 \mathrm{~cm}^{-1}$ and assigned to $\mathrm{C}_{3}-\mathrm{C}_{4}$ bond rotation, $\mathrm{C}=0$ bond stretching and $\mathrm{C}-\mathrm{O}-\mathrm{H}$ bending vibrations. The last band in the experimental spectrum, placed at $1757 \mathrm{~cm}^{-1}$ is reproduced theoretically at $1694 \mathrm{~cm}^{-1}$ and assigned to ring contractions (see Fig. 14.K), $\mathrm{C}=\mathrm{O}$ and $\mathrm{C}-\mathrm{O}$ bond stretching and $\mathrm{C}-\mathrm{O}-\mathrm{H}$ bending vibrations.

As for the deltic and squaric acids, several Raman bands attributable to $\mathrm{OH}$ stretching vibrations appear in the theoretical Raman spectrum (at 2282, 2313, 2334 and $2439 \mathrm{~cm}^{-1}$ ) and were not reported in the experimental works. 
Table 11. Observed ${ }^{20}$ and calculated Raman band wavenumbers $\left(\mathrm{cm}^{-1}\right)$ in the Raman spectrum of the croconic acid, irreducible representations, calculated intensities and assignments. The meaning of the acronyms T, Pr, El, Wi, Co, Be, Sh, R and Ap is given in Figure 14.

\begin{tabular}{|c|c|c|c|c|c|}
\hline $\begin{array}{l}\text { Band } \\
\text { name }\end{array}$ & $\begin{array}{c}\text { Exp. }^{20} \\
\text { Solid } \\
298 \text { K }\end{array}$ & $\begin{array}{c}\text { Calc. } \\
\text { (This work) }\end{array}$ & $\begin{array}{c}\text { Irr. } \\
\text { Rep. } \\
\text { (C2v) }\end{array}$ & $\begin{array}{l}\text { Int. } \\
\left(\AA^{4}\right)\end{array}$ & Assignment (This work) \\
\hline$a$ & - & 120.9 & $\mathrm{~A}_{1}$ & 77.16 & $\mathrm{~T}\left(\mathrm{C}_{5}\right)+\mathrm{T}(\mathrm{C}=\mathrm{O})+\mathrm{T}\left(\mathrm{OH}^{-}\right)$ \\
\hline$b$ & - & 151.5 & $A_{1}$ & 231.13 & $\delta^{\mathrm{oop}}(\mathrm{C}-\mathrm{O}-\mathrm{H})+\delta^{\mathrm{oop}}(\mathrm{C}-\mathrm{C}=0)$ \\
\hline$c$ & - & 242.7 & $\mathrm{~A}_{1}$ & 35.69 & $\mathrm{~T}\left(\mathrm{C}_{5}\right)+\delta^{\mathrm{oop}}(\mathrm{C}-\mathrm{C}=\mathrm{O})+\mathrm{T}\left(\mathrm{OH}^{-}\right)$ \\
\hline$d$ & - & 382.6 & $\mathrm{~A}_{2}$ & 20.84 & $\delta(\mathrm{C}-\mathrm{C}=0)+\mathrm{T}\left(\mathrm{OH}^{-}\right)$ \\
\hline$e$ & - & 407.3 & $\mathrm{~A}_{1}$ & 178.21 & “ \\
\hline$f$ & - & 506.4 & $A_{1}$ & 366.70 & $\operatorname{Pr}\left(\mathrm{C}_{5}\right)+\delta^{\mathrm{oop}}(\mathrm{C}-\mathrm{C}=0)+\delta^{\mathrm{oop}}(\mathrm{C}-\mathrm{O}-\mathrm{H})$ \\
\hline$g$ & 521 & 522.0 & $\mathrm{~A}_{1}$ & 329.00 & $\operatorname{Def}\left(\mathrm{C}_{5}\right)+v\left(\mathrm{C}_{2}-\mathrm{C}_{3}\right)+\delta^{\mathrm{oop}}(\mathrm{C}-\mathrm{C}=0)+\mathrm{T}\left(\mathrm{OH}^{-}\right)$ \\
\hline$h$ & 534 & 543.1 & $A_{1}$ & 536.01 & $\mathrm{El}\left(\mathrm{C}_{5}\right)+\mathrm{T}(\mathrm{C}=0)+\mathrm{T}(\mathrm{OH})$ \\
\hline$i$ & 553 & 547.3 & $\mathrm{~B}_{1}$ & 302.02 & “ \\
\hline$j$ & 565 & 561.3 & $\mathrm{~B}_{2}$ & 290.76 & $\mathrm{Wi}\left(\mathrm{C}_{5}\right)+\mathrm{T}(\mathrm{C}=0)+\mathrm{T}(\mathrm{OH})$ \\
\hline$k$ & 634 & 630.6 & $\mathrm{~A}_{1}$ & 2200.18 & $\mathrm{Co}\left(\mathrm{C}_{5}\right)+v(\mathrm{C}=\mathrm{O})+v(\mathrm{C}-\mathrm{O})+\delta(\mathrm{C}-\mathrm{O}-\mathrm{H})$ \\
\hline$l$ & 731 & 733.6 & $A_{1}$ & 36.51 & $\operatorname{Be}\left(\mathrm{C}_{5}\right)$ \\
\hline$m$ & 806 & 783.0 & $\mathrm{~B}_{1}$ & 5.0 & $\operatorname{Be}\left(\mathrm{C}_{5}\right)$ \\
\hline$n$ & 1074 & 1062.7 & $\mathrm{~A}_{1}$ & 286.78 & $\delta(\mathrm{C}-\mathrm{O}-\mathrm{H})$ \\
\hline$o$ & 1082 & 1080.9 & $\mathrm{~A}_{1}$ & 86.17 & “ \\
\hline$p$ & 1150 & 1151.7 & $\mathrm{~A}_{1}$ & 271.30 & “ \\
\hline \multirow[t]{2}{*}{$q$} & 1169 & 1165.2 & $\mathrm{~B}_{1}$ & 152.37 & $\mathrm{El}\left(\mathrm{C}_{2}-\mathrm{C}_{3}\right)+\mathrm{Sh}\left(\mathrm{C}_{3}-\mathrm{C}_{4}\right)+\mathrm{El}\left(\mathrm{C}_{4}-\mathrm{C}_{5}\right)+\delta(\mathrm{C}-\mathrm{O}-\mathrm{H})$ \\
\hline & & 1171.0 & $\mathrm{~B}_{2}$ & 128.12 & 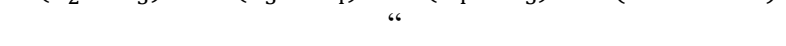 \\
\hline \multirow[t]{2}{*}{$r$} & 1236 & 1244.7 & $\mathrm{~A}_{1}$ & 670.63 & $\operatorname{Sh}\left(C_{5}-C_{1}\right)+\delta(C-0-H)$ \\
\hline & & 1257.2 & $\mathrm{~A}_{2}$ & 216.75 & “ \\
\hline$s$ & 1302 & 1310.0 & $\mathrm{~A}_{1}$ & 4291.03 & $\delta(\mathrm{C}-\mathrm{O}-\mathrm{H})$ \\
\hline \multirow[t]{2}{*}{$t$} & 1384 & 1377.7 & $\mathrm{~B}_{1}$ & 155.62 & “ \\
\hline & & 1397.0 & $\mathrm{~A}_{2}$ & 242.34 & “ \\
\hline$u$ & - & 1477.2 & $\mathrm{~A}_{1}$ & 448.02 & “ \\
\hline$v$ & 1522 & 1517.0 & $\mathrm{~A}_{1}$ & 1383.14 & “ \\
\hline \multirow[t]{3}{*}{$w$} & 1652 & 1552.2 & $\mathrm{~A}_{1}$ & 1148.94 & $\operatorname{Sh}\left(C_{3}-C_{4}\right)+\operatorname{Ro}\left(C_{4}-C_{5}\right)+v(C=0)+\delta(C-0-H)$ \\
\hline & & 1563.8 & $\mathrm{~B}_{2}$ & 1041.10 & $\mathrm{El}\left(\mathrm{C}_{3}-\mathrm{C}_{4}\right)+\mathrm{Ap}\left(\mathrm{C}_{2} \cdots \mathrm{C}_{5}\right)+v(\mathrm{C}=0)+\delta(\mathrm{C}-\mathrm{O}-\mathrm{H})$ \\
\hline & & 1576.5 & $\mathrm{~B}_{1}$ & 1183.85 & ( ) \\
\hline$x$ & 1722 & 1632.1 & $\mathrm{~A}_{1}$ & 3583.24 & $\mathrm{R}\left(\mathrm{C}_{3}-\mathrm{C}_{4}\right)+v(\mathrm{C}=0)+\delta(\mathrm{C}-\mathrm{O}-\mathrm{H})$ \\
\hline$y$ & 1757 & 1693.9 & $\mathrm{~A}_{1}$ & 3061.12 & $\mathrm{Co}\left(\mathrm{C}_{5}\right)+v(\mathrm{C}=\mathrm{O})+v(\mathrm{C}-\mathrm{O})+\delta(\mathrm{C}-\mathrm{O}-\mathrm{H})$ \\
\hline
\end{tabular}

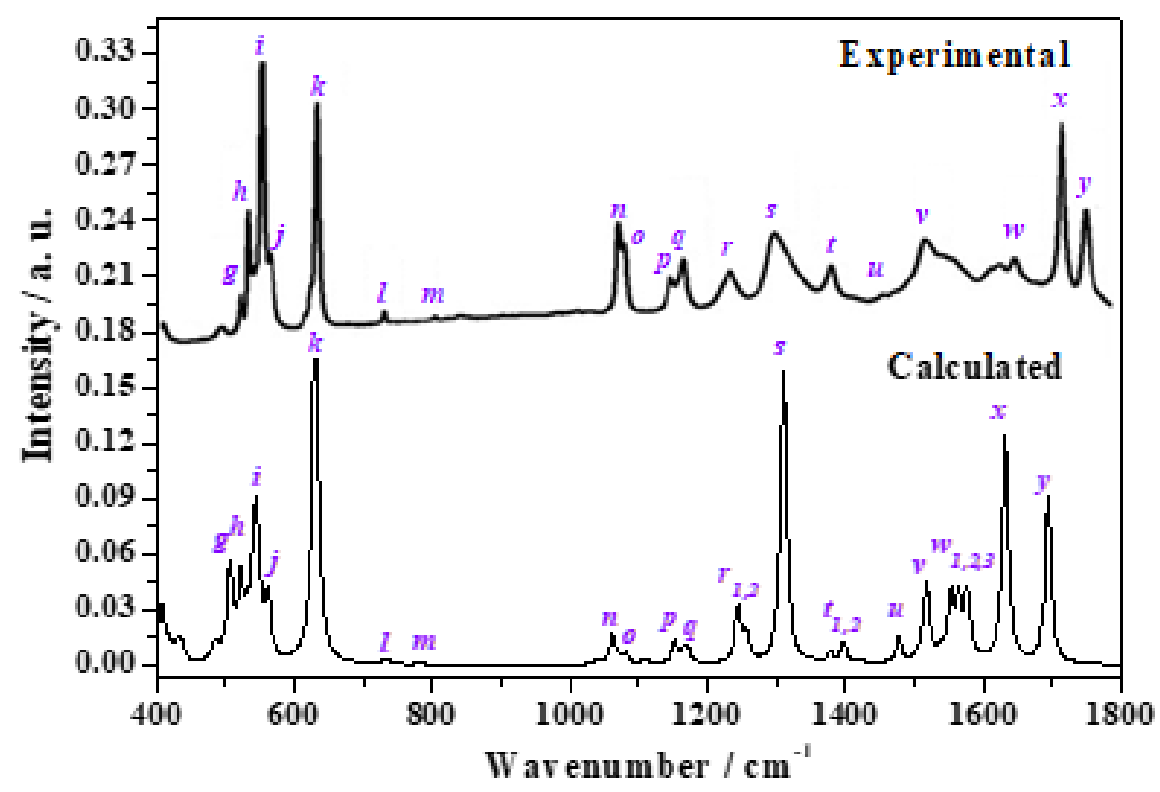

Figure 13. Experimental ${ }^{20}$ and calculated Raman spectra of the croconic acid. 

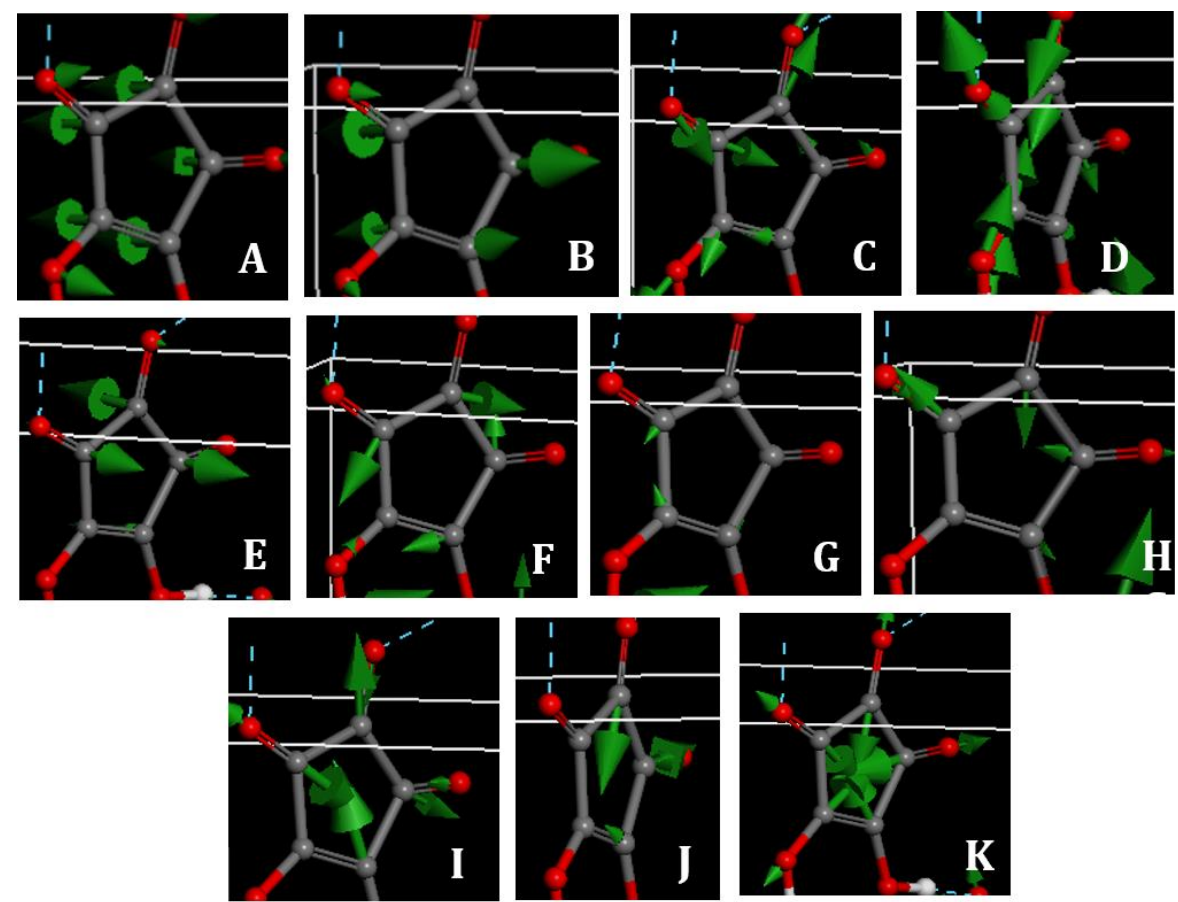

Figure 14. Motion types of the atoms of the $C_{5}$ carbon skeleton in the Raman active vibrational normal modes of the croconic acid: Vibrational motions involving the $\mathrm{C}_{5}$ carbon skeleton: (A) Translation, $\mathrm{T}\left(\mathrm{C}_{5}\right)\left[120.9,242.7 \mathrm{~cm}^{-1}\right]$; (B) Plane rotation, $\operatorname{Pr}\left(\mathrm{C}_{5}\right)[506.4 \mathrm{~cm}-1$ ]; $(\mathrm{C})$ Elongation, $\mathrm{El}\left(\mathrm{C}_{5}\right)\left[547.3 \mathrm{~cm}^{-1}\right]$; (D) Widening, Wi $\left(\mathrm{C}_{5}\right)\left[561.3 \mathrm{~cm}^{-1}\right]$; (E) Bending $\mathrm{Be}\left(\mathrm{C}_{5}\right)$ [733.6, 783.0, $\left.\mathrm{cm}^{-1}\right]$; $(\mathrm{F})$ Elongation of $\mathrm{C}_{2}-$ $\mathrm{C}_{3}$ and $\mathrm{C}_{4}-\mathrm{C}_{5}$ pentagon sides and $\mathrm{C}_{3}-\mathrm{C}_{4}$ side shortening, $\mathrm{El}\left(\mathrm{C}_{2}-\mathrm{C}_{3}\right)+\operatorname{Sh}\left(\mathrm{C}_{3}-\mathrm{C}_{4}\right)+\operatorname{El}\left(\mathrm{C}_{4}-\mathrm{C}_{5}\right)\left[1165.2,1171.0 \mathrm{~cm}{ }^{-1}\right] ;(\mathrm{G})$ $\mathrm{C}_{5}-\mathrm{C}_{1}$ side shortening, $\mathrm{Sh}\left(\mathrm{C}_{5}-\mathrm{C}_{1}\right)$ [1244.7, $\left.1257.2 \mathrm{~cm}^{-1}\right]$; $(\mathrm{H}) \mathrm{C}_{3}-\mathrm{C}_{4}$ pentagon side shortening and $\mathrm{C}_{4}-\mathrm{C}_{5}$ side rotation, $\operatorname{Sh}\left(C_{3}-C_{4}\right)+\operatorname{Ro}\left(C_{4}-C_{5}\right)\left[1552.2 \mathrm{~cm}^{-1}\right]$; (I) $C_{3}-C_{4}$ side elongation and $C_{2} \cdots C_{5}$ approach, $\operatorname{El}\left(C_{3}-C_{4}\right)+A p\left(C_{2} \cdots C_{5}\right)[1563.8$, $\left.1576.5 \mathrm{~cm}^{-1}\right]$; (J) $\mathrm{C}_{3}-\mathrm{C}_{4}$ side rotation, $\mathrm{R}\left(\mathrm{C}_{3}-\mathrm{C}_{4}\right)\left[1632.1 \mathrm{~cm}^{-1}\right]$; $(\mathrm{K})$ Contraction, $\mathrm{Co}\left(\mathrm{C}_{5}\right)\left[630.6,1693.9 \mathrm{~cm}^{-1}\right]$

\section{III.3. UV-Visible Optical Characterization}

\section{III.3.1. Band gaps}

The croconic, squaric and deltic acids are correctly predicted to be insulator materials in the present calculations, the computed band gaps being 1.80, 2.90 and $5.04 \mathrm{eV}$, respectively. However, as it is well-known, the band gaps are generally underestimated by the Density Functional Theory (DFT) methods in the generalized gradient approximation. ${ }^{94-99}$ The accurate estimation of the band gaps would need to go beyond DFT-PBE using for example hybrid functionals. As it has been shown computationally, ${ }^{94}$ for insulators, most of the differences between the DFT energy eigenvalues and the true excitation energies can be accounted for by a uniform shift of the unoccupied band energy levels. This way to deal with the band gap problem is so-called scissor correction. The shifting values for the croconic and squaric acids were 1.11 and $0.59 \mathrm{eV}$, respectively. The final values of the band gaps were 2.91 and $3.49 \mathrm{eV}$. These values were determined by adjusting the wavelength of the most intense peak in the computed UV-Vis absorption spectrum (see the next Sections) to the observed experimental wavelength for this peak. However, for deltic acid, the corresponding absorption spectrum has not been measured experimentally and, therefore, an average value of shifting constants obtained for the croconic and squaric acids, $0.85 \mathrm{eV}$, was used. When this shifting was applied the final band gap for value for deltic acid was $5.89 \mathrm{eV}$. It must be emphasized that the application of this correction does not modify the shape of the computed optical functions reported in the next sections.

\section{III.3.2. Croconic acid}

The computed UV-Vis absorption spectrum and the reflectivity, optical conductivity, dielectric, refractive index and loss optical functions of the croconic acid are shown in Figure 15. The calculated UV-Vis absorption spectrum, covering the wavelength range from 200 to $450 \mathrm{~nm}$, is displayed in Figure 15.A where it is compared with the experimental spectrum of Hartley et al. ${ }^{43}$ The remaining optical functions are plotted in the wavelength range $200-750 \mathrm{~nm}$. As can be seen in Figure 15.A, the agreement between the calculated absorption spectrum and the experimental one is quite good. The position of the four main peaks in the calculated absorption spectrum are given in Table 12. The origin of these peaks was obtained by analyzing the inter-band electronic transitions in the croconic acid. As it can be seen in Figure S.4 of the Supplementary Information, the peak $a$ located at $\lambda_{a}=299 \mathrm{~nm}$ results from the excitation of one electron from the occupied band with number $95(\sigma(C=C)+$ $\left.p_{y}(O)\right)$ to the unoccupied band number $107\left(p_{z}(C)+p_{x}(O)\right)$. Similarly, the peaks $b, c$ and $d$ at 314,333 and $351 \mathrm{~nm}$ are due to excitations from the occupied bands 97,99 and 97 to the unoccupied bands 109, 109 and 107, respectively, and represent mainly charge transfers from oxygen $p_{x}$ orbitals to carbon $p_{z}$ orbitals. 

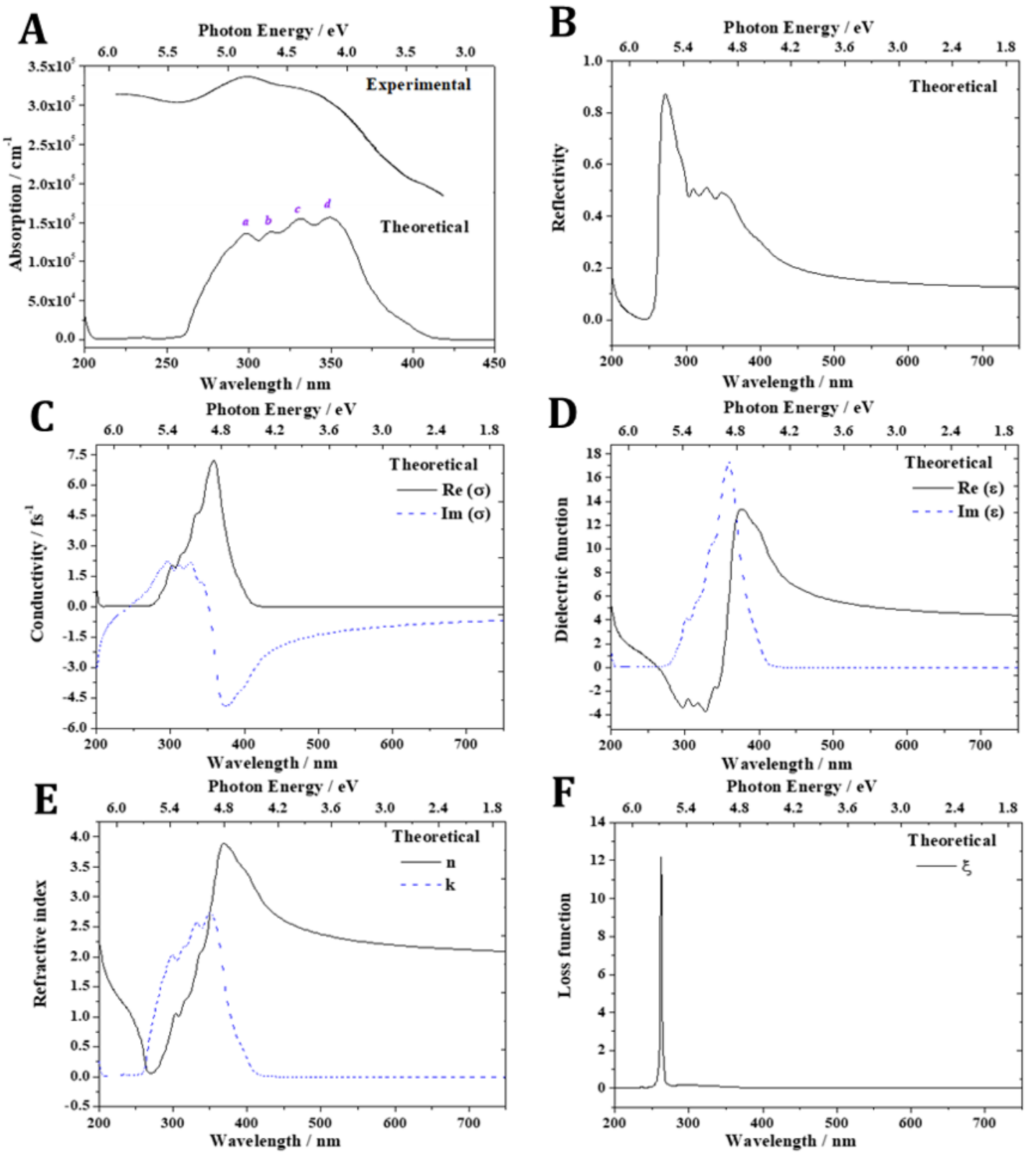

Figure 15. Computed and experimental ${ }^{43} \mathrm{UV}-\mathrm{Vis}$ absorption spectra and computed optical functions of the croconic acid.

Table 12. Calculated peaks in the calculated UV-Vis absorption spectra of the croconic, squaric and deltic acids.

\begin{tabular}{|c|c|c|c|c|}
\hline Peak name & Wavelength (nm) & Transition & Excitation energy $(\mathrm{eV})$ & Absorption $\left(\mathrm{cm}^{-1}\right)$ \\
\hline \multicolumn{5}{|c|}{ Croconic acid (highest occupied and lowest unoccupied bands: $\phi_{104}$ and $\phi_{105} ;$ band gap: $2.91 \mathrm{eV}$ ) } \\
\hline$a$ & $299 \pm 1$ & $\phi_{95}-\phi_{107}$ & $4.15 \pm 0.01$ & 135917.8 \\
\hline$b$ & $314 \pm 1$ & $\phi_{97}-\phi_{109}$ & $3.95 \pm 0.01$ & 137852.9 \\
\hline$c$ & $333 \pm 1$ & $\phi_{99}-\phi_{109}$ & $3.72 \pm 0.01$ & 155047.6 \\
\hline$d$ & $351 \pm 1$ & $\phi_{97}-\phi_{105}$ & $3.53 \pm 0.01$ & 156317.5 \\
\hline \multicolumn{5}{|c|}{ Squaric acid (highest occupied and lowest unoccupied bands: $\phi_{42}$ and $\phi_{43}$; band gap: $3.49 \mathrm{eV}$ ) } \\
\hline$a$ & $269 \pm 1$ & $\phi_{40}-\phi_{45}$ & $4.61 \pm 0.02$ & 231153.8 \\
\hline$b$ & $278 \pm 1$ & $\phi_{39}-\phi_{46}$ & $4.46 \pm 0.02$ & 192574.4 \\
\hline \multicolumn{5}{|c|}{ Deltic acid (highest occupied and lowest unoccupied bands: $\phi_{64}$ and $\phi_{65} ;$ band gap: $5.89 \mathrm{eV}$ ) } \\
\hline$a$ & $179 \pm 1$ & $\phi_{64}-\phi_{66}$ & $6.93 \pm 0.04$ & 289221.3 \\
\hline
\end{tabular}




\section{III.3.3. Squaric acid}

The computed UV absorption spectrum and the reflectivity, optical conductivity, dielectric, refractive index and loss optical functions of the squaric acid are shown in Figure 16. The calculated UV absorption spectrum, covering the wavelength range from 220 to $350 \mathrm{~nm}$, is displayed in Figure 16.A compared with the experimental spectrum from the Bio-Rad Laboratories Spectral Database. ${ }^{44}$ As for croconic acid, the remaining optical functions are plotted in the wavelength range $200-750 \mathrm{~nm}$. As can be seen in Figure 16.A, the shape of the calculated and experimental absorption spectra is quite similar. The position of two peaks of the calculated absorption spectrum are given in Table 12. The peak $a$ at $\lambda_{a}=269 \mathrm{~nm}$ (see Figure S.4 of the Supplementary Information), results from the excitation of one electron from the occupied band with number 40 to the unoccupied band number 45 and represents a charge transfer from $\pi$ orbitals to $\pi^{*}$ orbitals. Similarly, the peak $b$ at $\lambda_{b}=378 \mathrm{~nm}$ is due to an excitation from the occupied band 39 to the unoccupied band number 46 and represents a similar type of charge transfer $\left(\pi \rightarrow \pi^{*}\right)$.
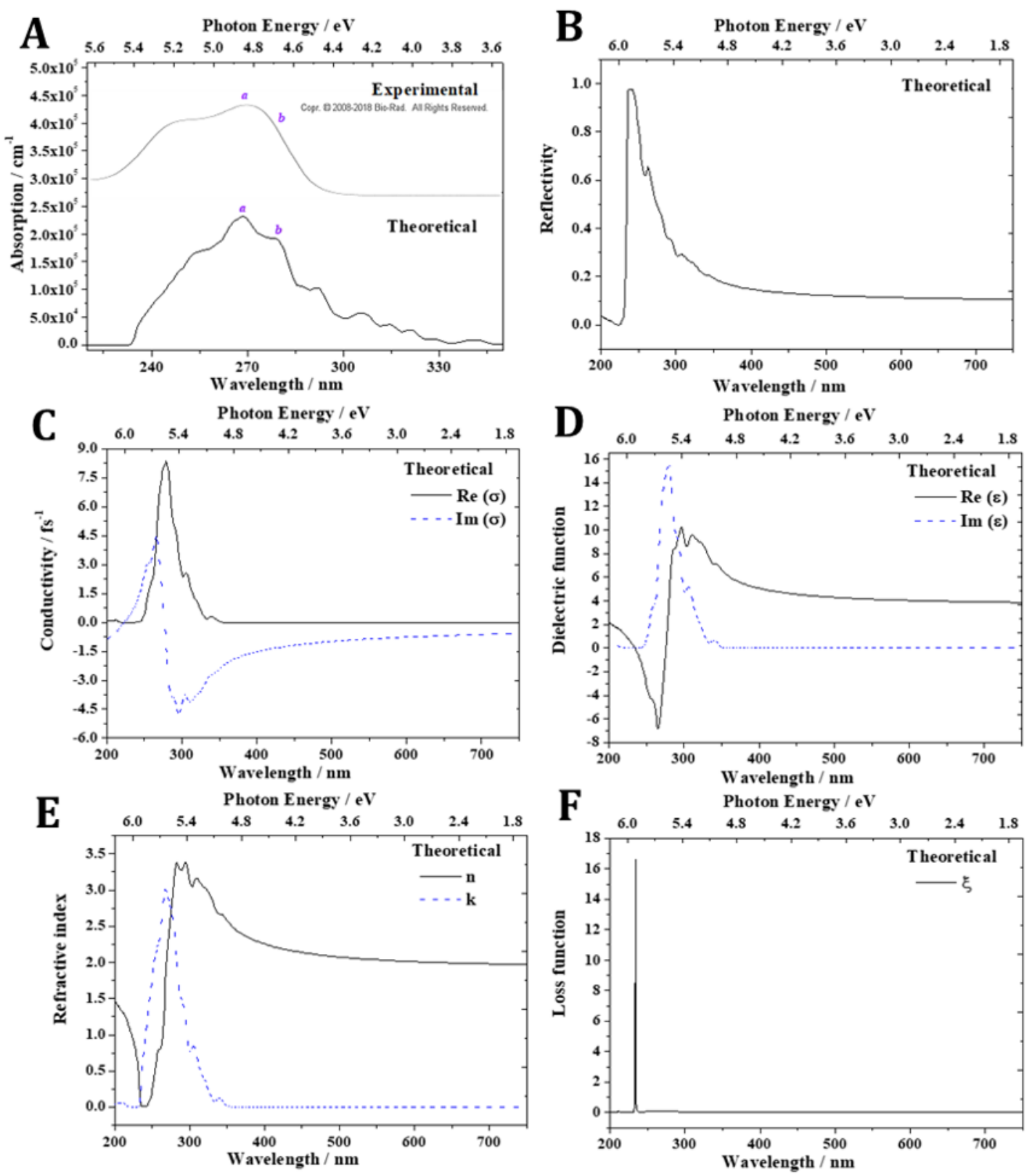

Figure 16. Computed and experimental ${ }^{44} \mathrm{UV}$ absorption spectra and optical functions of the squaric acid. 

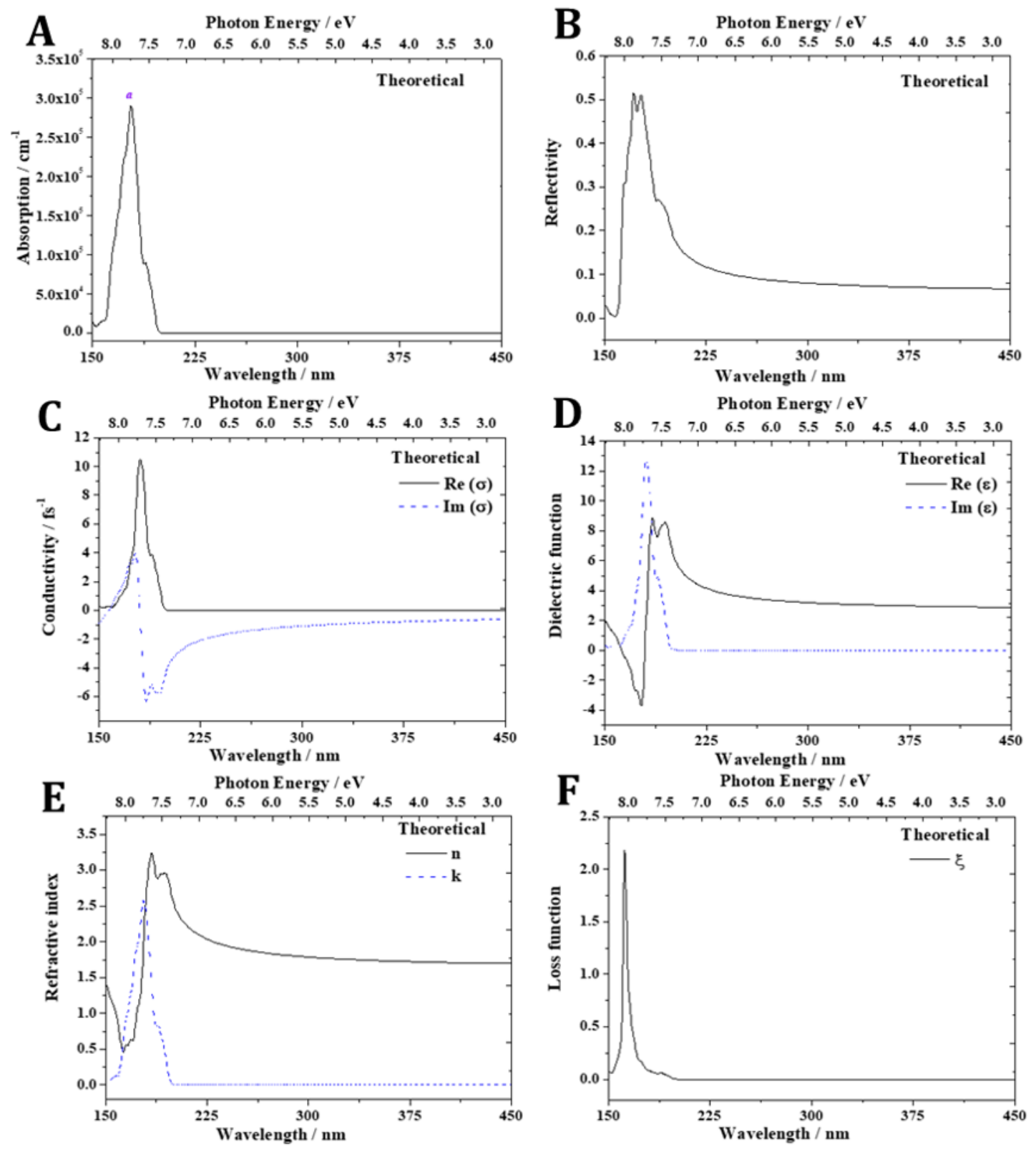

Figure 17. Computed UV-Vis absorption spectra and optical functions of the deltic acid.

\section{III.3.4. Deltic acid}

The computed UV-Vis absorption spectrum and optical functions of the deltic acid are shown in Figure 17. The calculated UV absorption spectrum, covering the wavelength range from 220 to $350 \mathrm{~nm}$, is displayed in Figure 17.A. The position of the main peak in the calculated absorption spectrum is found at 179 $\mathrm{nm}$ (see Table 12). This peak (see Figure S.4 of the Supplementary Information), results from the excitation of one electron from the occupied band with number 64 to the unoccupied band number 66 . This transition represents mainly a $\left(\pi \rightarrow p_{z}(C)\right)$ charge transfer.

\section{CONCLUSIONS}

A complete characterization of the thermodynamic, Raman spectroscopic and ultraviolet-visible optical properties of the deltic, squaric and croconic cyclic oxocarbon acids has been performed by employing a computational approach based on theoretical solid-state methods. The computational study was carried out using very demanding calculation parameters, better that usually used in this kind of studies, in order to provide a realistic characterization of these materials. While these important materials have been studied at length experimentally, their characterization was relatively poor. One of the most surprising features of this study is that the characterization of their Raman spectra, being very accurately recorded and published in a large number of excellent spectroscopic studies, ${ }^{7-23}$ was not reliable. This is due to the use of the empirical method of assignment as the only source of information, surely for lack of relevant theoretical solid-state calculations. The assumption of the transferability of the information from gas or liquid phase spectroscopic data to crystalline solids is very crude and leads 
to significant problems. The assignment of the bands in their Raman spectrum was also very incomplete. Most bands were reassigned. This study points to the need of using more elaborate methods of spectral assignment.

The fundamental thermodynamic properties, including the specific heat, the entropy, the enthalpy and the Gibbs free energy as well as their temperature dependence were also obtained. The calculated specific heat of the squaric acid, one of the only properties known from experimental measurements, was in good agreement with the corresponding experimental value. The thermodynamic properties obtained for the three materials where then used to determine the thermodynamic properties of formation of these materials in terms of the elements as a function of temperature. In turn, the calculated thermodynamic properties of formation were used to evaluate the Gibbs free energies of reaction and associated reaction constants for the reactions of thermal decomposition, complete combustion and interconversion of the squaric and croconic acids. The experimental enthalpies of combustion of the croconic and squaric acids at room temperature were also well reproduced.

Finally, the ultraviolet-visible absorption spectrum and the reflectivity, optical conductivity, dielectric, refractive index and loss optical functions of the three materials were determined. The UV-Vis absorption spectra calculated for the croconic and squaric acids were in good agreement with their experimental counterparts and that of deltic acid, which has not been obtained experimentally, was predicted. The origin of the peaks in the absorption spectra of these materials was found by examining the inter-band electronic transitions in these materials.

\section{SUPPORTING INFORMATION}

Supporting Information associated with this article contain: (a) Computed thermodynamic functions of the deltic, squaric and croconic acids; (b) Pictures of the atomic motions associated to active Raman normal modes of these materials; $(c)$ Calculated UV-Vis absorption spectra and optical functions.

\section{AUTHOR INFORMATION}

\section{Corresponding Author}

*E-mail: francisco.colmenero@iem.cfmac.csic.es.

Phone number: +34 915616800 Ext. 941033.

ORCID. Francisco Colmenero: 0000-0003-3418-0735.

\section{ACKNOWLEDGMENT}

Supercomputer time by the CTI-CSIC center is greatly acknowledged. One of the authors (RE) was supported by the Ministry of Science, Innovation and Universities within the Project FIS2016-77726-C3-1-P.

\section{REFERENCES}

(1) West, R. (ed.) Oxocarbons. New York: Academic Press, 1980.

(2) West, R.; Niu, N. Y.; Powell, D. L.; Evans, M. V. Symmetrical Resonance Stabilized Anions. $\mathrm{C}_{\mathrm{n}} \mathrm{O}_{\mathrm{n}}^{2-}$. J. Am. Chem. Soc. 1960, 82, 6204-6205.
(3) Leibovici, C. Theoretical Analysis of the Structure of Monocyclic Oxocarbon Dianions $\left[\mathrm{C}_{n} \mathrm{O}_{n}\right]^{2-}(\mathrm{n}=3,4,5,6)$. J. Mol. Struct. 1972, 13, 185-189.

(4) Moyano, A.; Serratosa, F. A Simple Model for the Electronic Structure of Oxocarbon Dianions. J. Mol. Struct. 1982, 90, 131-136.

(5) Seitz, G.; Imming, P. Oxocarbons and Pseudooxocarbons. Chem. Rev. 1992, 92, 1227-1260.

(6) Colmenero, F. Anomalous Mechanical Behavior of the Deltic, Squaric and Croconic Cyclic Oxocarbon Acids. Mat. Res. Express 2019, 6, 045610.

(7) Lautié, A.; Lautié, M. F.; Novak, A. Étude Vibrationnelle des Acides Deltiques $\mathrm{C}_{3} \mathrm{O}_{3} \mathrm{H}_{2}$ et $\mathrm{C}_{3} \mathrm{O}_{3} \mathrm{D}_{2}$. Can. J. Chem. 1985, 63, 1394-1398.

(8) Lautié, A.; Lautié, M. F.; Novak, A. Vibrational Spectra and Valence Force Field Calculation of Deltic Acid. J. Mol. Struct. 1986, 142, 29-32.

(9) West, R.; Eggerding; D.; Perkins, J.; Handy. D.; Tuazon, E. C. New Aromatic Anions. 11. Vibrational Spectra and Force Constants for Deltate Ion, $\mathrm{C}_{3} \mathrm{O}_{3}^{2-}$. J. Am. Chem. Soc. 1979, 101, 1710-1714.

(10) Junqueira, G. M. A; Rocha, W. R.; De Almeida, W. B.; Dos Santos, H. Theoretical Analysis of the Oxocarbons: The Role Played by the Solvent and Counter-Ions in the Electronic Spectrum of the Deltate Ion. Phys. Chem. Chem. Phys. 2002, 4, 2517-2523.

(11) Baglin F. G.; Rose, C. B. The Infrared and Raman Spectra of Crystalline Squaric Acid. Spectrochim. Acta A 1970, 26, 2293-2304.

(12) Nakashima, S.; Balkanski, M. Raman Study of Squaric Acid. Solid State Commun. 1976, 19, 1225-1228.

(13) Georgopoulos, S. L.; Edwards., H. G. M.; De Oliveira, L. F. C. Raman Spectroscopic Analysis of the Interaction between Squaric Acid and Dimethylsulfoxide. Spectrochim. Acta A 2013, 111, 54-61.

(14) Junqueira, G. M. A; Rocha, W. R.; De Almeida, W. B.; Dos Santos, H. Theoretical Analysis of the Oxocarbons: The Solvent and Counter-Ion Effects on the Structure and Spectroscopic Properties of the Squarate Ion. Phys. Chem. Chem. Phys. 2003, 5, 437-445.

(15) Ito, M.; West, R. New Aromatic Anions. IV. Vibrational Spectra and Force Constants for $\mathrm{C}_{4} \mathrm{O}_{4}^{2-}$ and $\mathrm{C}_{5} \mathrm{O}_{5}^{2-}$. J. Am. Chem. Soc. 1963, 85, 2580-2584.

(16) D. Bougeard; Novak, A. Vibrational Study of Squaric Acid. Solid State Commun. 1978, 27, 453-457.

(17) Thackeray, D. P. C.; Shirley, R.; Stace, B. C. The Structure and Spectra of Squaric Acid. Solid State Commun. 1978, 27, 453-457.

(18) Georgopoulos, S. L.; Diniz, R; Rodrigues, B. L.; De Oliveira, L. F. C. Crystal Structure and Raman Spectra of Rubidium Hydrogen Squarate. J. Mol. Struct. 2005, 741, 61-66.

(19) Georgopoulos, S. L.; Diniz, R; Yoshida, M. I.; Speziali, N. L.; Dos Santos, H. F.; Junqueira, G. M. A.; De Oliveira, L. F. C. Vibrational Spectroscopy and Aromaticity Investigation of Squarate Salts: A Theoretical and Experimental Approach. J. Mol. Struct. 2006, 794, 63-70. 
(20) Milán-Garcés, E. A.; Georgopoulos, S. L.: Sant'Ana, C.; Andrade, G. F. S.; De Oliveira, L. F. C. Chemical Behavior of Croconic acid Coordinated to Co(II) Adsorbed on Silver Surface. J. Raman Spectrosc. 2018, 49, 1174-1183.

(21) Junqueira, G. M. A; Rocha, W. R.; De Almeida, W. B.; Dos Santos, H. Theoretical Analysis of the Oxocarbons: Structure and Spectroscopic Properties of Croconate Ion and its Coordination Compound with Lithium. Phys. Chem. Chem. Phys. 2001, 3, 3499-3505.

(22) Santos, P. S. The Resonance Raman Effect of Dithiocroconate. J. Mol. Struct. 1990, 216, 1-7.

(23) Santos, P. S.; Amaral, J. H.; Oliveira, L. F. C. Raman Spectra of Some Transition Metal Squarate and Croconate Complexes. J. Mol. Struct. 1991, 243, 223-232.

(24) Colmenero, F.; Timon, V. Study of the Structural, Vibrational and Thermodynamic Properties of Natroxalate Mineral Using Density Functional Theory. J. Solid State Chem. 2018, 263, 131-140.

(25) Colmenero, F. Structural, Spectroscopic, and Thermodynamic Characterization of Ammonium Oxalate Monohydrate Mineral Using Theoretical Solid-State Methods. J. Phys. Chem. Solids 2019, 125, 31-42.

(26) Armstrong, G. T.; Domalski, E. S.; Inscoe, M. N.; Halou, I.; Furukawa, G. T.; Buresh, M. K. Thermodynamic Properties of the Compounds of the Elements CHNOPS. National Bureau of Standards Report 8906. National Aeronautics and Space Administration, 1965.

(27) Domalsky, E. S. Selected Values of Heats of Combustion and Heats of Formation of Organic Compounds Containing the Elements C, H, N, O, P, and S. J. Phys. Chem. Ref. Data 1972, 1, 221-277.

(28) Domalski, E. S.; Evans, W. H.; Hearing, E. D. Heat Capacities and Entropies of Organic Compounds in the Condensed Phase. J. Phys. Chem. Ref. Data 1984, 13, Suppl.1, 1286; 1990, 19, 1075.

(29) Domalski, E. S.; Hearing, E. D. Heat Capacities and Entropies of Organic Compounds in the Condensed Phase. Volume II. J. Phys. Chem. Ref. Data 1990, 19, 881-1047.

(30) Domalski, E. S.; Hearing, E. D. Heat Capacities and Entropies of Organic Compounds in the Condensed Phase. Volume III. J. Phys. Chem. Ref. Data 1996, 25, 1-523; 1997, 26, 1501.

(31) Domalski, E. S.; Hearing, E. D. Estimation of the Properties of Hydrocarbons at 298.15 K. J. Phys. Chem. Ref. Data 1988, 17, 1637-1678.

(32) Wilhoit, R. C..; Chao, J.; Hall, K. R. Thermodynamic Properties of Key Organic Oxygen Compounds in the Carbon Range C1 to C4. Part 1. Properties of Condensed Phases. J. Phys. Chem. Ref. Data 1985, 14, 1-175.

(33) Afeefy, H. Y.; Liebman, J. F.; Stein, S. E. Neutral Thermochemical Data. In: NIST Chemistry Webbook; NIST Standard Reference Database No. 69. Linstrom, P. J., Mallard, W. G., (eds.). National Institute of Standards and Technology: Gaithersburg, MD. http://webbook.nist.gov.

(34) Ciezak-Jenkins, J. A.; Gottfried, J. L.; Pesce-Rodriguez, R. A. Thermal and Laser-Induced Shock Characterization of
Oxocarbon Acids. US Army Research Laboratory Report ARL-TR-6924, 2014.

(35) Isert, S.; Ciezak-Jenkins, J. A. Investigation and Characterization of Water-Recrystallized Croconic Acid. US Army Research Laboratory Report ARL-TR-7910, 2016.

(36) Azizi, N.; Saki, E. I.; Edrisi, M. Squaric Acid as an Impressive Organocatalyst for Michael Addition in Water. C. $R$. Chimie 2011, 14, 973-977.

(37) Lakes, R. S. Foam Structures with a Negative Poisson's Ratio. Science 1987, 235, 1038-1040.

(38) Greaves, G. N.; Greer, A. L.; Lakes, R. S.; Rouxel, T. Poisson's Ratio and Modern Materials. Nature Mater. 2011, 10, 823-837.

(39) Lakes, R. S. Negative-Poisson's-Ratio Materials: Auxetic Solids. Annu. Rev. Mater. Res. 2017, 47, 63-81.

(40) Baughman, R. H.; Stafström, S.; Cui, S.; Dantas, S. O. Materials with Negative Compressibilities in One or More Dimensions. Science 1998, 279, 1522-1524.

(41) Kornblatt, J. A.; Sirota, E. B.; King, H. E.; Baughman, R. H.; Cui, C. Materials with Negative Compressibilities. Science 1998, 281, 143.

(42) Cairns, A. B.; Goodwin, A. L. Negative Linear Compressibility. Phys. Chem. Chem. Phys. 2005, 17, 20449-20465.

(43) Hartley, K. K.; Woff, A. R.; Travis, L. D. Croconic Acid: An Absorber in the Venus Clouds? Icarus 1989, 77, 382-390.

(44) Bio-Rad Laboratories Spectral Database. https://spectrabase.com/spectrum/7LPchiCHk2D, accessed December 15,2018

(45) Wooten, F. Optical Properties of Solids. New York: Elsevier, 1972.

(46) Dresselhaus, M. S. Solid State Physics. II. Optical Properties of Solids. Vol. 6 (2001). http://web.mit.edu/6.732/www/ opt.pdf, accessed December 15, 2018.

(47) Fox, M. Optical Properties of Solids. Oxford: Oxford University Press, 2001.

(48) Terpetschning, E.; Szmacinski, H.; Ozinskas, A.; Lakowicz, J. R. Synthesis of Squaraine-N-hydroxysuccinimide Esters and their Biological Application as Long-Wavelength Fluorescent Labels. Anal. Biochem. 1994, 1217, 197-204.

(49) Oswald, B.; Patsenker, L.; Duschl, J.; Szmacinski, H.; Wolfbeis, O. S.; Terpetschnig, E. Synthesis, Spectral Properties, and Detection Limits of Reactive Squaraine Dyes, a New Class of Diode Laser Compatible Fluorescent Protein Labels. Bioconj, Chem. 1999, 10, 925-931.

(50) Yasui, S.; Matsuoka, M.; Kitao, T. Syntheses and Some Properties of Infrared-Absorbing Croconium and Related Dyes. Dyes Pigm. 1988, 10, 13-22.

(51) Fabian, J.; Nakazumi, H.; Masuoka, M. Near-Infrared Absorbing Dyes. Chem. Rev. 1992, 92, 1197-1226.

(52) Keil, D.; Hartmann, H.; Reichardt, C. Synthesis and Spectroscopic Characterization of New NIR Absorbing (2Thienyl)- and (4-Dialkylaminoaryl)-substituted Croconic Acid Dyes. Liebigs Ann. Chem. 1993, 9, 935-939. 
(53) Encinas, C.; Otazo, E.; Rivera, L.; Miltsova, S.; Alonso, J. Croconines: New Acidochromic Dyes for the Near Infrared Region. Tetrahedron Lett. 2002, 43, 8391-8393.

(54) Payne, M. C.; Teter, M. P.; Ailan, D. C.; Arias, A.; Joannopoulos, J. D. Iterative Minimization Techniques for $\mathrm{Ab}$ Initio Total-Energy Calculations: Molecular Dynamics and Conjugate Gradients. Rev. Mod. Phys. 1992, 64, 1045-1097.

(55) Perdew, J. P.; Burke, K.; Ernzerhof, M. Generalized Gradient Approximation Made Simple. Phys. Rev. Lett. 1996, 77, 3865-3868.

(56) Grimme, S. Semiempirical GGA-type Density Functional Constructed with a Long-Range Dispersion Correction. J. Comput. Chem. 2006, 27, 1787-1799.

(57) Baroni, S.; de Gironcoli, S.; Dal Corso, A. Phonons and Related Crystal Properties from Density-Functional Perturbation Theory. Rev. Mod. Phys. 2001, 73, 515-562.

(58) Gonze, X.; Lee, C. Dynamical Matrices, Born Effective Charges, Dielectric Permittivity Tensors, and Interatomic Force Constants from Density-Functional Perturbation Theory. Phys. Rev. B 1997, 55, 10355-10368.

(59) Refson, K.; Tulip, P. R.; Clark, S. J. Variational DensityFunctional Perturbation Pheory for Dielectrics and Lattice Dynamics. Phys. Rev. B 2006, 73, 155114.

(60) Clark, S. J.; Segall, M. D.; Pickard, C. J.; Hasnip P. J.; Probert, M. I. J.; Refson, K.; Payne, M. C. First Principles Methods Using CASTEP. Z. Kristallogr. 2005, 220, 567-570.

(61) MaterialsStudio, http://3dsbiovia.com/products/collaborative-science/biovia-materials-studio/, accessed September 27, 2018.

(62) Bonales, L. J.; Colmenero, F.; Cobos, J.; Timón, V. Spectroscopic Raman Characterization of Rutherfordine: a Combined DFT and Experimental Study. Phys. Chem. Chem. Phys. 2016, 18, 16575-16584.

(63) Colmenero, F.; Bonales, L. J.; Cobos, J.; Timón, V. Study of the Thermal Stability of Studtite by In Situ Raman Spectroscopy and DFT Calculations. Spectrochim. Acta. A 2017, 174, 245-253.

(64) Colmenero, F.; Bonales, L. J.; Cobos, J.; Timón, V. Structural, Mechanical and Vibrational Study of Uranyl Silicate Mineral Soddyite by DFT Calculations. J. Solid. State Chem. 2017, 253, 249-257.

(65) Colmenero, F.; Bonales, L. J.; Cobos, J.; Timón, V. Structural, Mechanical and Raman Spectroscopic Characterization of Layered Uranyl Silicate Mineral Uranophane- $\alpha$ by DFT Methods. Clay Miner. 2018, 53, 377-392.

(66) Colmenero, F.; Cobos, J.; Timón, V. Periodic DFT Study of the Structure, Raman Spectrum and Mechanical Properties of Schoepite Mineral. Inorg. Chem. 2018, 57, 4470-4481.

(67) Colmenero, F. Theoretical Studies of the Structural, Mechanic and Raman Spectroscopic Properties of Uranyl Containing Minerals. In: Minerals. K. S. Essa (ed.). London: InTechOpen, 2018. ISBN: 978-953-51-6784-6.

(68) Colmenero, F. Mechanical Properties of Anhydrous Oxalic Acid and Oxalic Acid Dihydrate. Phys. Chem. Chem. Phys. 2019, 21, 2673-2690.
(69) Colmenero, F. Negative Area Compressibility in Oxalic Acid Dihydrate. Mat. Lett. 2019, 245, 25-28.

(70) Colmenero, F. Addendum: Anomalous Mechanical Behavior of the Deltic, Squaric and Croconic Cyclic Oxocarbon Acids. Mat. Res. Express. 2019, 6, 069401.

(71) Colmenero, F.; Cobos, J.; Timón, V. Negative Linear Compressibility in Uranyl Squarate Monohydrate J. Phys.: Cond. Matter. 2019, 31, 175701.

(72) Colmenero, F.; Bonales, L. J.; Cobos, J.; Timón, V. Density Functional Theory Study of the Thermodynamic and Raman Vibrational Properties of $\gamma-\mathrm{UO}_{3}$ Polymorph. J. Phys. Chem. C 2017, 121, 14507-14516.

(73) Colmenero, F.; Fernández, A. M.; Cobos, J.; Timón, V. Thermodynamic Properties of Uranyl Containing Materials Based on Density Functional Theory. J. Phys. Chem. C 2018, 122, 5254-5267.

(74) Colmenero, F.; Fernández, A. M.; Cobos, J.; Timón, V. Temperature Dependent Free Energies of Reaction of Uranyl Containing Materials Based on Density Functional Theory. J. Phys. Chem. C 2018, 122, 5268-5279.

(75) Colmenero, F.; Fernández, A. M.; Timón, V.; Cobos. J. Becquerelite Mineral Phase: Crystal Structure and Thermodynamic and Mechanic Stability by Using Periodic DFT. RSC Adv. 2018, 8, 24599-24616.

(76) Colmenero, F.; Fernández, A. M.; Cobos, J.; Timón V. DFT Study of the Thermodynamic Properties and Stability of Schoepite and Metaschoepite Mineral Phases. ACS Earth Space Chem. 2019, 3, 17-28.

(77) Colmenero, F.; Cobos, J.; Timón, V. Periodic Density Functional Theory Study of the Raman Spectrum of the Hydrated Uranyl Oxyhydroxide Mineral Becquerelite. Theor. Chem. Acc. 2019, 138, 43.

(78) Colmenero, F.; Bonales, L. J.; Cobos, J., Timón, V. Thermodynamic and Mechanical Properties of Rutherfordine Mineral Based on Density Functional Theory. J. Phys. Chem. C 2017, 121, 5994-6001.

(79) Colmenero, F. Revealing Rutherfordine Mineral as an Auxetic Material. Appl. Sci. 2018, 8, 2281-2290.

(80) Lee, C.; Gonze, X. Ab Initio Calculation of the Thermodynamic Properties and Atomic Temperature Factors of $\mathrm{SiO}_{2}$ $\alpha$-Quartz and Stishovite. Phys. Rev. B 1995, 51, 8610-8613.

(81) Colmenero, F. The Application of Periodic Density Functional Theory to the Study of Uranyl Containing Materials: Thermodynamic Properties and Stability. In: Density Functional Theory. D. Glossman-Mitnik (ed.). London: InTechOpen, 2018. ISBN: 978-953-51-7020-4.

(82) Chase, M. W.; Davies, C. A.; Downey, J. R.; Frurip, D. J.; McDonald, R. A.; Syverud, A. N. JANAF Thermochemical Tables. Third Edition. J. Phys. Chem. Ref. Data 1985, 14, Suppl. 1, 1-1856.

(83) Cox, J.D.; Angus, S.; Armstrong, G. T.; Freeman, R. D., Laffite, M.; Schneider, G. M.; Somsen, G., Alcock, C. B. Notation for States and Processes, Significance of the Word Standard in Chemical Thermodynamics, and Remarks on Commonly Tabulated Forms of Thermodynamic Functions. Pure Appl. Chem. 1982, 54, 1239-1250. 
(84) Hutter, J. Excited State Nuclear Forces from the TammDancoff Approximation to Time-Dependent Density Functional Theory within the Plane Wave Basis Set Framework. J. Chem. Phys. 2003, 118, 3928-3934.

(85) Semmingsen, D.; Hollander, F. J.; Koetzle, T. F. A Neutron Diffraction Study of Squaric Acid (3,4-Dihydroxy-3-Cyclobutene-1,2-Dione). J. Chem. Phys. 1977, 66, 4405-4412.

(86) Hollander, F. J.; Semmingsen, D.; Koetzle, T. F. The Molecular and Crystal Structure of Squaric Acid (3,4-Dihydroxy3-Cyclobutene-1,2-Dione) at $121^{\circ} \mathrm{C}$ : A Neutron Diffraction Study. J. Chem. Phys. 1977, 67, 4825-4831.

(87) Samuelsen, E. J.: Semmingsen, D. The Phase Transition of Two-Dimensional Squaric Acid $\mathrm{H}_{2} \mathrm{C}_{4} \mathrm{O}_{4}$ Studied by Neutron Scattering. J. Phys. Chem. Solids 1977, 38, 1275-1283.

(88) Feder, J. Two-Dimensional Ferroelectricity. Ferroelectrics $1976,12,71-84$

(89) Barth, E.; Helwig, R. J.; Maier, H. D.; Müser, H. E.; Petersson, J. Specific Heat of the Two-Dimensional Antiferroelectric Squaric Acid. Z. Physik B 1979, 34, 393-397.

(90) De Wit, H. G. M.; Offringa, J. C. A.; De Kruif, C. G.; VanMiltenburg, J. C. Thermodynamic Properties of Molecular Organic Crystals Containing Nitrogen, Oxygen and Sulfur. III. Molar Heat Capacities Measured by Differential Scanning Calorimetry. Thermochim. Acta 1983, 65, 43-51.

(91) Sellers, P. Enthalpies of Formation of Squaric Acid and the Corresponding Diethyl Ether. Acta Chem. Scand. 1971, 25, 2194-2198.

(92) Lee, K. S.; Kweon, J. J.; Oh, I. H.; Lee, C. E. Polymorphic Phase Transition and Thermal Stability in Squaric Acid $\left(\mathrm{H}_{2} \mathrm{C}_{4} \mathrm{O}_{4}\right)$. J. Phys. Chem. Solids 2012, 73, 890-895.

(93) Serratosa, F. Acetylene Diethers: A Logical Entry to Oxocarbons. Acc. Chem. Res. 1983, 16, 170-176.

(94) Godby, R. W. Exchange and Correlation in Solids. Top. Appl. Phys. 1992, 69, 51-88.

(95) Xu, X.; Goddard, W. A. The Extended Perdew-Burke-Ernzerhof Functional with Improved Accuracy for Thermodynamic and Electronic Properties of Molecular Systems. J. Chem. Phys. 2004, 121, 4068-4082.

(96) Liao, W.-Q.; Zhang, Y.; Hu, C.-L.; Mao, J.-G.; Ye, H.-Y.; Li, P.-F.; Huang, S. D.; Xiong, R.-G. A Lead-Halide Perovskite Molecular Ferroelectric Semiconductor. Nat. Commun. 2015, 6, No. 7338.

(97) Bian, Q.; Yang, Z.; Wang, Y.; Cao, C.; Pan, S. Predicting Global Minimum in Complex Beryllium Borate System for Deep-Ultraviolet Functional Optical Applications. Sci. Rep. 2016, 6, No. 34839.

(98) Ding, S.; Zhang, H.; Zhang, Q.; Chen, Y.; Dou, R.; Peng, F.; Liu, W.; Sun, D. Experimental and First Principle Study of the Structure, Electronic, Optical and Luminescence Properties of M-type $\mathrm{GdNbO}_{4}$ Phosphor. J. Solid State Chem. 2018, 262, 87-93.

(99) Kalashnyk, N.; Perry, D. L.; Massuyeau, F.; Faulques, E. Exploring Optical and Vibrational Properties of the Uranium Carbonate Andersonite with Spectroscopy and FirstPrinciples Calculations. J. Phys. Chem. C 2018, 122, 7410-7420. 


\section{TOC Graphic}

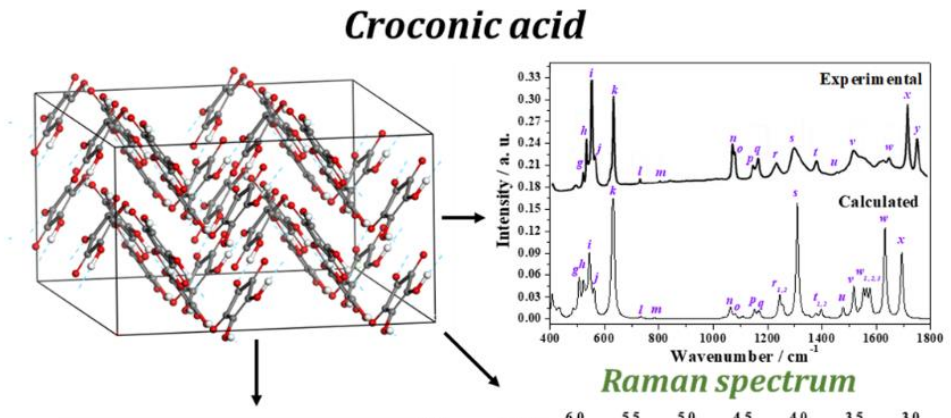

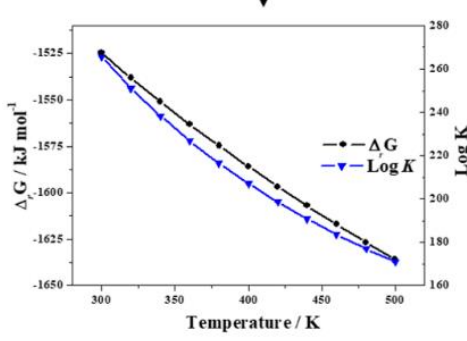

Enthalpy of combustion

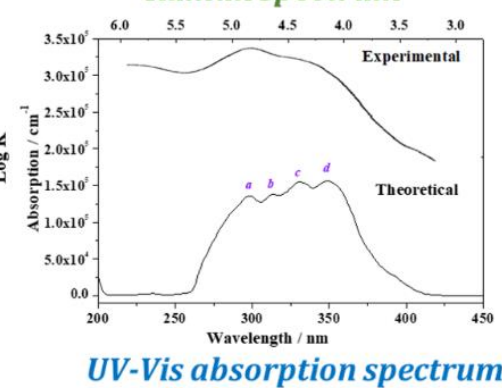

